\title{
CAMBIO SOCIAL Y MODERNIZACION EN LA ESPAÑA ACTUAL
}

José Félix Tezanos

Sin duda alguna, uno de los rasgos que más claramente definen al hombre de nuestro tiempo es la profunda vivencia del cambio. Las transformaciones de toda índole que puso en marcha la revolución industrial, así como el fenomenal proceso de innovaciones científicas y tecnológicas que estamos viviendo, han venido a caracterizar a nuestra época como una era de importantes cambios y mutaciones de toda índole. En nuestros días una sola generación puede vivir cambios difíciles de imaginar, a veces casi de ciencia-ficción; lo cual era algo insólito hace muy poco tiempo. Pensemos que la géneración más adulta actualmente viva, pasó su adolescencia en un mundo sin aviones, sin automóviles en las calles, sin televisión, sin cine sonoro, sin electrodomésticos, sin computadoras, sin radio, sin antibióticos, con unos niveles medios de vida bastante inferiores a los más bajos de nuestro tiempo y, en su conjunto, en un contexto social tan distinto al actual que casi podría decirse que a lo largo de sus años ha vivido en dos tipos de sociedades diferentes, en dos países distintos: o lo que es lo mismo, ha tenido una vivencia casi de emigrantes, sin necesidad de moverse de sitio.

En un contexto de esta índole, en el que al cambio científico y tecnológico se une un acelerado proceso de cambio social, con trascendentales modificaciones en los sistemas de producción, que dan lugar a importantes transformaciones en las estructuras de clase, no es de extrañar que para la so- 
ciología contemporánea la idea de cambio se haya convertido en más prevalente que la de estructura. Por ello, en nuestro tiempo, el análisis de la estructura de cualquier sociedad ha de ser necesariamente un análisis enfocado desde la perspectiva del cambio, es decir, desde la óptica de las transformaciones que se están operando en sus estructuras sociales.

\section{LA IMPORTANCIA DEL CAMBIO SOCIAL EN LA ESPAÑA ACTUAL}

Desde una perspectiva histórica, quizá, aún no se ha valorado suficientemente cómo esta vivencia generalizada del cambio está influyendo en diferentes facetas de la personalidad humana, que, de esta manera, se está viendo sometida, de formas más o menos sutiles o drásticas, a permanentes procesos de ajustes adaptativos, que contrastan con las situaciones contextuales de mayor estabilidad, propias de las sociedades rural-tradicionales de hace muy poco tiempo. Así, podría decirse que el ciudadano de las sociedades urbano-industriales de nuestro tiempo se encuentra sometido a medio plazo a «tensiones» en cierta medida similares a aquellos procesos de adaptación típicos de los emigrantes que - también en relación a sus efectos críticos- han sido estudiados con tanto detenimiento por algunos sociólogos.

A su vez, la propia intensidad de los cambios, con sus requerimientos adaptativos (en formación, en prácticas sociales y costumbres, en modas y gustos, y hasta en lenguajes), está teniendo un importante efecto de agrandamiento de las diferencias generacionales. Entre un joven español actual y sus padres o sus abuelos, por ejemplo, puede haber muchas más diferencias que entre estos últimos y sus antepasados de hace dos, o tres, o incluso cuatro siglos, al tiempo que las diferencias entre un joven español de nuestros días y un joven americano, o alemán, o japonés, son infinitamente menores a las existentes mutuamente entre sus abuelos y bisabuelos. En definitiva, esta nueva situación a lo que está dando lugar, entre otras cosas, es a que los conflictos generacionales tengan hoy en día una importancia bastante mayor en el marco general de los conflictos sociales globales, que la que tenía hace sólo unos pocos lustros.

Sin embargo, la situación real de cambio no sólo configura un requerimiento metodológico en el análisis social, sino que ha llegado también a constituir un importante horizonte vital para los hombres de nuestro tiempo, mucho más atentos y receptivos, ahora, a las posibilidades del cambio y de la innovación social, y, en definitiva, más propensos a interiorizar de manera bastante generalizada el objetivo del cambio como una aspiración, también personal, en el camino hacia la utopía de una sociedad mejor.

En este contexto general, y refiriéndonos más inmediatamente al caso concreto de España, resulta indudable que el tema del cambio social tiene actualmente una enorme importancia, tanto sociológica como política; y ello 
por varias razones. En primer lugar, por la magnitud del proceso de cambio social ocurrido en España en la segunda mitad del siglo xx y que de manera tan importante ha modificado su faz social. En segundo lugar, por las especiales circunstancias de falta de transparencia en que se produjo ese proceso de cambio, como consecuencia de los esquemas autoritarios y dictatoriales imperantes durante el franquismo. $Y$, en tercer lugar $-\mathrm{y}$ como consecuencia de lo anterior-, por todos los desajustes y tensiones a que dio lugar un proceso de cambio en el que no siempre existía acomodación y armonía entre lo que ocurría a nivel socioeconómico y lo que ocurría a nivel político. Así, por una parte, el franquismo supuso un poderoso freno al cambio político, que a su vez acabó dificultando y conflictualizando determinados aspectos del cambio socioeconómico. De igual manera el franquismo, al impedir una vida política normal, creando un largo paréntesis de vacío político durante casi cuarenta años, dificultó la racional organización social de la defensa de los intereses sociales y políticos, así como el ajuste de los intereses económicos.

Como consecuencia, tanto de lo dilatado del paréntesis franquista, como de la importancia de los cambios sociales ocurridos durante dicho tiempo, se acabó produciendo una situación en la que el adecuamiento entre el subsistema político y el subsistema social no resultaba todo lo fluida que es en cualquier sistema mínimamente ajustado. Ello dio lugar, por ejemplo, a que en los primeros años de la «transición democrática» los partidos «supervivientes» del período pre-franquista tuvieran que hacer un enorme esfuerzo de adaptación a las nuevas circunstancias sociales del país. Por otra parte, nos encontramos, también, con que durante este largo paréntesis ciertos grandes partidos de la derecha se acabaron volatilizando por completo. Es el caso, por ejemplo, de la otrora poderosa CEDA, con su bien específica significación socioeconómica. Algo similar ha acontecido, también, con los partidos republicanos de centro y centro-izquierda.

Si a esto añadimos que fuerzas sociopolíticas, antaño tan poderosas como la CNT, han visto extraordinariamente mermados sus apoyos; que las formaciones políticas que constituyeron el sustrato ideológico del franquismo, como la Falange y el Requeté, han quedado prácticamente barridas de la arena política; o incluso, que un partido tan importante en la «transición» como la UCD, ha desaparecido después de estar cinco años en el Gobierno, comprenderemos hasta qué punto la situación política española ha presentado también durante la transición importantes facetas de cambio, e incluso de crisis de ajuste de intereses, a la búsqueda de nuevos equilibrios.

$\mathrm{Y}$ a partir de estos hechos, lo que muchos se preguntan es si en nuestro actual abanico parlamentario están representados todos los intereses políticos y socioeconómicos que tienen vigencia en la España actual, o lo que es más importante, si están representados de una manera correcta y no distorsionada. Ciertas volatizaciones ¿son fruto del cambio social? Ciertas nuevas formaciones emergentes ¿son —o fueron- fruto del mismo cambio?, ¿o quizá lo son 
$\longrightarrow$ fueron- de la inercia del franquismo? ¿Los actuales partidos políticos responden claramente a los intereses de las diferentes clases sociales y grupos de interés identificables en nuestra estructura de clases? ¿Qué intereses de clase representan los actuales partidos de la derecha? ¿Pueden ser considerados como partidos estables frente a cualquier contingencia electoral? ¿Cómo han influido - y van a influir - en el mapa político actual las transformaciones acontecidas en la estructura de clases durante este período? ¿Hay indicios de que se puedan producir nuevos desajustes entre actividad política y realidad social?

Estas y otras muchas preguntas similares constituyen, sin duda, parte importante de los interrogantes que sociólogos, politólogos y muchos otros ciudadanos, se plantean en estos momentos, con una grave y responsable preocupación por que la actividad política discurra en España sin que se produzca el riesgo de un divorcio con los datos de la realidad social que pueda conducir a nuevos callejones políticos sin salida. Para evitar tales riesgos, obviamente, es necesario, entre otras cosas, realizar con la máxima exactitud que permiten los datos disponibles - y la misma fluidez de toda situación sociopolítica- un constante análisis de la estructura y la dinámica de la sociedad española actual.

\section{PRINCIPALES CAMBIOS EN LA ESTRUCTURA SOCIAL ESPAÑOLA}

Desde principio de siglo hasta nuestros días y especialmente en el período posterior a la guerra civil, se han producido tales cambios en la realidad social que no es exagerado decir que la España actual se ha convertido en una sociedad casi completamente diferente. Como señalaba Salvador Giner en 1971, «lo que ha ocurrido desde 1939 es una transformación muy profunda de todas las estructuras sociales, salvo las de la clase dominante y el sistema de poder y autoridad sobre el que ésta se apoya. Por una parte, nos encontramos con la disminución drástica del proletariado rural, de la población agraria; con la diversificación ocupacional de las clases obreras y media; con cambios importantes de mentalidad y conducta en muchos niveles; con aumentos sustanciales de la movilidad geográfica y vertical; con aumentos en volumen de ciertos sectores clave: estudiantes, intelectuales, técnicos» ${ }^{1}$.

Pero la verdad es que, más allá de la intensidad del proceso de cambio, estas transformaciones se han caracterizado por su carácter discontinuo y, a veces, un tanto incoherente. Muchos cambios se produjeron, durante el

1 SALvador GiNer, "La estructura social de España", en Horizonte español 1972, tomo 2, París, Ruedo Ibérico, 1979, p. 41. Este artículo es una versión algo ampliada del capítulo sobre "Social stratification in Spain", aparecido en Margaret SCOTFORd ARCHER y Salvador GINER (eds.), Contemporary Europe. Class Status and Power, Londres, Weidenfeldd \& Nicholson, 1971. 
régimen político franquista, de una manera caótica, sin que existieran previsiones ni planificación alguna, llegando a suponer unos enormes costes sociales y resultando, en ocasiones, bastante traumáticos para muchos ciudadanos.

Por supuesto, es imposible hacer aquí un inventario completo y detallado de todas las transformaciones sociales que se han producido durante este período de tiempo, así como de las consecuencias que éstas han tenido. Por ello nos vamos a limitar a señalar esquemáticamente algunos de los principales cambios sociales, tal como éstos pueden ser vistos, especialmente, desde la perspectiva de la década de los años ochenta.

\section{Crecimiento demográfico descompensado}

De los 18 millones de habitantes que España tenía en el umbral de este siglo, de acuerdo con los datos del censo de 1900, hemos pasado a 37.680.960, según datos censales referidos a $1981^{2}$, lo cual ha supuesto pasar de una densidad de población de 36,8 habitantes por $\mathrm{Km}^{2}$ en 1900 a una densidad de 74,6 habitantes por $\mathrm{Km}^{2}$ en 1981 .

A partir de estos datos se puede considerar que España, dada su extensión, y en comparación con otros países europeos, es un país aún no muy poblado, teniendo en cuenta, por ejemplo, que en 1980 la densidad de habitantes por $\mathrm{Km}^{2}$ era de 345 en los Países Bajos, de 323 en Bélgica, de 247,2 en Alemania, de 229,5 en Inglaterra, de 189,2 en Italia, de 140,8 en Luxemburgo, de 118,9 en Dinamarca, de 98 en Francia, etc. ${ }^{3}$. Sin embargo, lo más destacable de la población española no sólo es su mayor o menor volumen, sino la manera desigual en que se encuentra repartida por toda nuestra geografía. Así, por ejemplo, según datos del censo de 1981, mientras la densidad demográfica alcanzaba cifras de 597 habitantes por $\mathrm{Km}^{2}$ en provincias como la de Barcelona, 591 en Madrid, 532 en Vizcaya, etc., en provincias como Soria, en cambio, sólo llegaba a los nueve habitantes por $\mathrm{Km}^{2}$, a 10 en Teruel, a 11 en Guadalajara, a 12 en Cuenta, etc. A su vez, en determinados muncipios, se está produciendo una verdadera sobrecongestión de población. Este es el caso, por ejemplo, de municipios como Hospitalet, con una densidad de 24.589 habitantes por $\mathrm{Km}^{2}$, según el censo de 1981 (según el censo de 1960 la densidad era de 5.582), de Barcelona capital con 19.260 habitantes por $\mathrm{Km}^{2}$ (17.119 en 1960), de Portugalete con 19.357 (7.528 en 1960), de Santa Coloma de Gramanet con 20.088 (4.656 en 1960), etc. Para podernos hacer una idea de lo que estas cifras significan, hay que tener en cuenta, por ejemplo, que la densidad de población de Madrid era de 5.203 habitantes en 1981, de 5.183 en 1970 y de 3.723 habitantes por $\mathrm{Km}^{2}$ en 1960 ,

${ }^{2}$ Instituto Nacional de Estadística, Censo de Población 1981. Avance de resultados, Madrid, 1984.

${ }^{3}$ United Nations, Statistical Yearbook 1981, Nueva York, 1983, pp. 61 y ss. 
por no hablar de la situación existente en algunas ciudades menores como Zaragoza con 539 habitantes por $\mathrm{Km}^{2}$ en 1981, Oviedo con 997, Alicante con 1.236, Málaga con 1.240, Burgos con 1.439, Córdoba con 224, Jaén con 227, así como un buen número de capitales de provincias más pequeñas con densidades por debajo de los 300 y aún los 200 habitantes por $\mathrm{Km}^{24}$.

$\mathrm{La}$ agudización de estas tendencias, que obviamente reflejan no sólo el incremento de la población por la vía de la natalidad, sino también la fuerte incidencia de las migraciones interiores, puede acabar dividiendo al país en áreas de sobrecongestión de población y áreas de progresiva desertización. Esta situación ha permitido a los demógrafos establecer previsiones que dibujan, para un futuro inmediato, un panorama en el que la población española, de no producirse modificaciones en las tendencias actuales, quedará localizada en algunos islotes en la meseta y en la franja costera, en tanto que amplias zonas de nuestra geografía quedarán casi despobladas ${ }^{5}$. De hecho, en 1984, tal como podemos ver en el mapa 1, la diferente densidad de población por provincias, permite comprobar la existencia de un perfil de mayor poblamiento en las franjas costeras, en contraste con las menores densidades de población en las provincias de la meseta, con la isla de Madrid.

\section{MAPA 1}

Densidad de población por provincias (número de habitantes por $\mathrm{Km}^{2}$ )

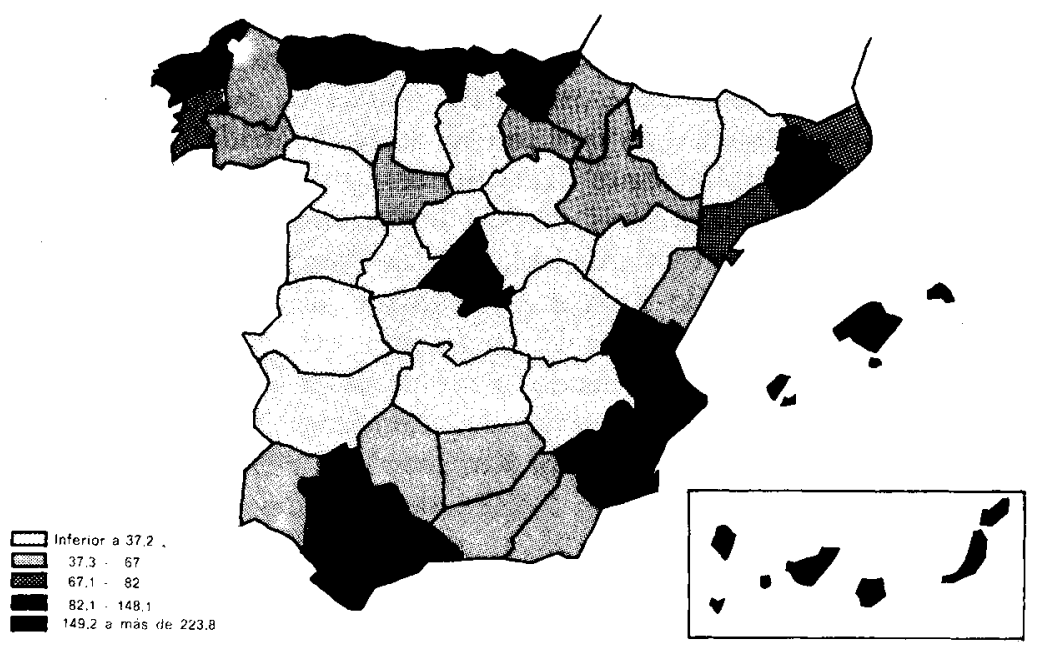

4 INE, Censo de población de 1981, op. cit.

s Algunos demógrafos, economistas y sociólogos han complementado estas previsiones señalando la existencia de un triángulo de especial atracción de población (y riqueza): se trata del triángulo formado por Madrid y las que algunos han llamado las "regiones-bisagra" de la puerta europea: Cataluña y País Vasco. 
Las consecuencias de este tipo de distribución de la población y la manera en que las migraciones interiores están afectando la misma conformación y evolución de la situación socioeconómica de las regiones, según veremos más adelante, ponen de relieve la gravedad de los problemas que pueden acabar planteándose como consecuencia de la falta de una verdadera política de planificación social. De hecho, por ejemplo, en el período intercensal 1970-1981, nos encontramos con que regiones como Madrid han visto crecer su población en un 24,6 por 100 , Baleares en un 23,1 por 100 , Canarias en un 21,5 por 100 , Valencia en un 18,5 por 100 , Cataluña en un 16,6 por 100 , Murcia en un 14,8 por 100 , el País Vasco en un 14,7 por 100 , etc., en tanto que regiones como Extremadura la han visto decrecer en un 8,9 por 100 , Castilla-La Mancha en un 4,8 por 100 y Castilla-León en un 3,2 por $100^{6}$.

Por otra parte, al igual que en el resto de los países industrializados, se ha producido en los últimos años un cambio en el modelo de evolución demográfica; cambio que viene caracterizado por un descenso de la mortalidad, una disminución de la natalidad y, en consecuencia, un envejecimiento de la población. Este cambio afecta a la estructura demográfica de una manera que hace que las pirámides de población vayan perdiendo su tradicional perfil rigurosamente piramidal, para adquirir una conformación más oblonga como consecuencia del aumento del número de personas de más edad y la paralela disminución de las de menos edad.

En España este proceso de transición demográfica se ha producido con un cierto retraso y singularidad respecto a los restantes países europeos. Así la reducción de la mortalidad catastrófica —especialmente epidémica- hay que situarla en el umbral del siglo $\mathrm{xx}$, la reducción de la mortalidad ordinaria -especialmente infantil- en los años que coinciden con la I Guerra Mundial, y el descenso de la tasa de la natalidad, muy lentamente, puede observarse a partir de nuestra guerra civil, con ciertos períodos de crecimiento, sin que hasta fechas recientes se hayan alcanzado tendencias realmente homologables con las de otros países industrializados ${ }^{7}$.

Así, tal como podemos ver en los datos de la tabla 1, las tasas de nata-

- INE, La población de España. Censo de 1981, p. 27.

T La datación concreta de la fecha en que se produjo en España el definitivo descenso de la natalidad dio lugar a una cierta polémica entre sociólogos y demógrafos españoles sobre la verdadera interpretación del significado del influjo de la guerra civil del 36 en la evolución de la natalidad, así como sobre el grado en que existió una estabilización posterior de ésta, e incluso indicios de crecimiento. Sobre dicho tema pueden verse: Salustiano del Campo, Análisis de la población de España, Barcelona, Ariel, 1972, y La política demográfica en España, Madrid, Edicusa, 1974. Juan DfEz NIColÁs, "La transición demográfica en España", Revista de Estudios Sociales, núm. 1, Madrid, 1971; Amando de Miguru, Sexo, mujer y natalidad en España, Madrid, Edicusa, 1974, donde se incluye un resumen de la polémica. Sobre el tema de la población española, en general, puede verse también el ulterior trabajo de divulgación de Joaquín LEGuINA, Quiénes son los habitantes de España, Barcelona, La Gaya Ciencia, 1977, y más recientemente el número monográfico sobre Sociología de la población en España de la Revista Española de Investigaciones Sociológicas, abril-junio 1980, núm. 10. 


\section{TABLA 1}

Movimiento natural de la población española desde principios de siglo (Tasas por 1.000 habitantes)

\begin{tabular}{|c|c|c|c|c|c|c|c|c|}
\hline & & Años & & & Nupcialidad & Natalidad & Mortalidad & $\begin{array}{l}\text { Crecimiento } \\
\text { vegetativo }\end{array}$ \\
\hline 1900 & . & $\begin{array}{llll}\ldots & \ldots & \ldots\end{array}$ & $\begin{array}{ll}\ldots & \ldots\end{array}$ & $\ldots$ & 8,67 & 33,76 & 28,86 & 4.90 \\
\hline 1910 & $\ldots$ & $\begin{array}{lll}\ldots & \ldots & \ldots\end{array}$ & $\ldots \ldots$ & $\ldots$ & 7,02 & 32,58 & 22,97 & 9,61 \\
\hline 1920 & $\ldots$ & $\ldots \ldots \ldots$ & $\ldots \ldots$ & $\ldots$ & 8,27 & 29,36 & 23,29 & 6,07 \\
\hline 1930 & $\ldots$ & $\begin{array}{llll}\ldots & \ldots & \ldots\end{array}$ & $\ldots \quad \ldots$ & $\ldots$ & 7,42 & 28,19 & 16,83 & 11,36 \\
\hline 1940 & $\ldots$ & $\begin{array}{lll}\ldots & \ldots & . .\end{array}$ & ... $\ldots$ & $\ldots$ & 8,38 & 24,37 & 16,50 & 7,87 \\
\hline 1950 & $\ldots$ & $\begin{array}{llll}\ldots & \ldots & . .\end{array}$ & $\ldots \ldots$ & $\ldots$ & 7,50 & 20,06 & 10,80 & 9,26 \\
\hline 1960 & $\ldots$ & $\begin{array}{lll}\ldots & \ldots & \end{array}$ & $\ldots \ldots$ & $\ldots$ & 7,79 & 21,60 & 8,65 & 12,95 \\
\hline 1970 & $\ldots$ & $\begin{array}{llll}\ldots & \ldots & \ldots\end{array}$ & $\ldots \quad \ldots$ & $\ldots$ & 7,36 & 19,50 & 8,33 & 11,17 \\
\hline 1971 & $\ldots$ & $\begin{array}{lll}\ldots & \ldots & \end{array}$ & $\ldots \ldots$ & $\ldots$ & 7,44 & 19,62 & 9,00 & 10,62 \\
\hline 1972 & $\ldots$ & $\begin{array}{llll} & \ldots & \ldots & \ldots\end{array}$ & $\ldots \quad \ldots$ & $\ldots$ & 7,64 & 19,46 & 8,25 & 11,21 \\
\hline 1973 & $\ldots$ & $\begin{array}{lll}\ldots & \ldots & \ldots\end{array}$ & $\ldots \ldots$ & $\ldots$ & 7,75 & 19,30 & 8,64 & 10,66 \\
\hline 1974 & $\ldots$ & $\begin{array}{lll}\ldots & \ldots & \ldots\end{array}$ & $\ldots \ldots$ & $\ldots$ & 7,63 & 19,56 & 8,52 & 11,04 \\
\hline 1975 & $\ldots$ & $\begin{array}{llll}\ldots & \ldots & \ldots\end{array}$ & $\begin{array}{ll}\ldots & \ldots\end{array}$ & $\ldots$ & 7,64 & 18,85 & 8,40 & 10,45 \\
\hline 1976 & $\ldots$ & $\begin{array}{lll}\ldots & \ldots & . .\end{array}$ & $\ldots \ldots$ & $\ldots$ & 7,26 & 18,85 & 8,32 & 10,53 \\
\hline 1977 & $\ldots$ & $\begin{array}{llll}\ldots & \ldots & \ldots\end{array}$ & $\ldots \quad \ldots$ & $\ldots$ & 7,20 & 18,05 & 8,09 & 9,95 \\
\hline 1978 & $\ldots$ & $\begin{array}{llll}\ldots & \ldots & \ldots\end{array}$ & $\begin{array}{ll}\ldots & \ldots\end{array}$ & $\ldots$ & 7,02 & 17,32 & 8,07 & 9,21 \\
\hline 1979 & $\ldots$ & $\begin{array}{llll}\ldots & \ldots & \ldots\end{array}$ & $\begin{array}{ll}\ldots & \ldots\end{array}$ & $\ldots$ & 6,64 & 16,22 & 7,85 & 8,38 \\
\hline 1980 & $\ldots$ & $\begin{array}{llll}\ldots & \ldots & \ldots\end{array}$ & $\begin{array}{ll}\ldots & \ldots\end{array}$ & $\ldots$ & 5,71 & 15,12 & 7,69 & 7,43 \\
\hline 1981 & $\ldots$ & $\begin{array}{llll}\ldots & \ldots & \ldots\end{array}$ & $\ldots \quad \ldots$ & $\ldots$ & 5,29 & 14,14 & 7,60 & 6,53 \\
\hline 1982 & $\ldots$ & $\begin{array}{llll}\ldots & \ldots & \ldots\end{array}$ & $\ldots \ldots$ & $\ldots$ & 4,97 & 13,43 & 7,44 & 5,99 \\
\hline
\end{tabular}

Fuentes: INE, España Panorámica Social 1974, op. cit., p. 55; Movimiento Natural de la Población Española 1979, Madrid, 1984, p. 132, y Anuario Estadistica 1984, p. 47 (elaboración propia).

lidad experimentaron una caída importante a lo largo de la década de los años 70 , siendo precisamente a partir del año 76 cuando esta caída se va a intensificar, hasta que ya en 1982 es, prácticamente, la mitad de lo que era en los años 30 y 40 . Por otra parte, la tasa de mortalidad ha experimentado un descenso muy considerable a lo largo de la primera mitad del siglo, siendo su descenso más lento y sostenido a partir de 1960. A su vez, la tasa de nupcialidad ha experimentado una caída importante desde finales de la década de los años 70. Este hecho, unido al descenso de las edades medias de entrada en el matrimonio, tal como podemos ver en la tabla 2, refleja sin duda significativas transformaciones en las prácticas matrimoniales a las que más adelante nos referiremos. De momento, es importante subrayar aquí, no obstante, que nuestra tasa de nupcialidad en 1982 era más baja, por ejemplo, que la existente en países como Noruega $(5,4)$, Italia $(5,5)$, Suiza $(5,6)$, Francia (5,8), Países Bajos (5,9), República Federal de Alemania (5,9), Irlanda (5,9), Japón (6), Austria $(6,3)$, Bélgica $(6,5)$, Hungría $(7,1)$, Inglaterra $(7,1)$, Grecia $(7,4)$, Canadá $(7,6)$, Australia $(7,7)$, Polonia $(8,7)$, Estados Unidos $(10,8)$, etc. ${ }^{8}$.

${ }^{8}$ United Nations, Demographic Yearbook 1982, Nueva York, 1984, pp. 482 y ss. 
En su conjunto, la evolución de la curva de crecimiento vegetativo dibuja un perfil ascendente que alcanza su punto más alto en 1960 , con una ulterior tendencia de crecimiento lento hasta la mitad de la década de los años 70, siendo precisamente en el período comprendido entre 1976 y 1982 en el que se va a producir un descenso más significativo de la tasa de crecimiento vegetativo, con lo que nuestro país va a empezar a situarse, precisamente en un período de transición política, en unas coordenadas de evolución de la población más similares a las de los restantes países europeos e industrializados.

\section{TABLA 2}

Evolución de las edades medias de entrada en el matrimonio en España desde principios del siglo $X X$

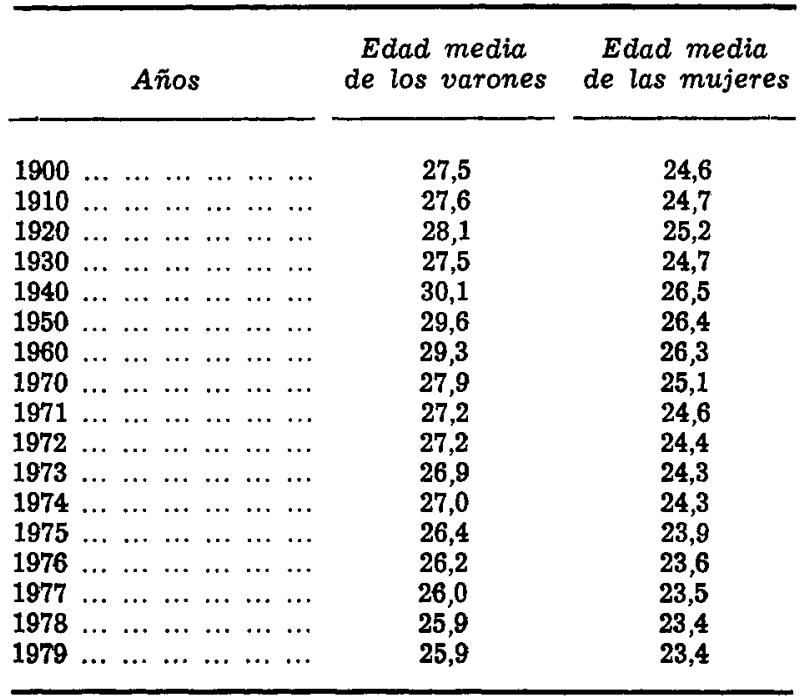

Fuentes: INE, España. Panorámica social, op. cit., p. 68; Movimiento natural de la población española. Año 1979, Madrid, 1984, p. 135.

Sin duda alguna, en el retraso con que se ha producido el proceso de transición demográfica en España, y aun en las diferencias actuales entre nuestras tasas de natalidad y las de algunos países europeos, han estado influyendo no sólo factores socioeconómicos, sino también políticos y religiosos. Recordemos, en este sentido, la política natalista del franquismo, así como el influjo de prejuicios religiosos y también, claro está, toda la política orientada a impedir y dificultar la propaganda y difusión de métodos de control de la natalidad. 
Desde otra perspectiva, hay que señalar que la tendencia hacia un envejecimiento de la población no adquiere caracteres verdaderamente significativos hasta el Censo de 1950, si bien desde principios de siglo es detectable una progresiva tendencia al envejecimiento, con importantes incrementos en la población de más de 65 años, que pasa de representar un 5,2 por 100 de los habitantes en el Censo de 1900 , a un 6,1 por 100 en el de 1930 , siendo un 7,2 por 100 en el de 1950, un 9,7 por 100 en el de 1970, para llegar, finalmente, a un 11,3 por 100 en el de 1981 .

Especialmente acusado resulta, en este sentido, el envejecimiento de la población que se ha producido en determinadas regiones y provincias españolas. Así, por ejemplo, según datos del censo de 1981, la población mayor de 65 años alcanzaba una proporción del 18,5 por 100 en Soria, del 18,2 por 100 en Lugo, del 17,7 por 100 en Teruel, del 17,5 en Zamora, del 17,4 por 100 en Cuenca, del 16,9 por 100 en Guadalajara, del 16,6 por 100 en Orense, etc. Si a esto añadimos que, paralelamente, en estas provincias la proporción de habitantes menores de 14 años está por debajo del 21 por 100 -en comparación con un 25,6 por 100 en la media nacional-, con casos, incluso, como los de Teruel con sólo un 17,1 por 100 de habitantes menores de 14 años, o el de Lugo con un 18,2 por 100, comprenderemos hasta qué punto el futuro inmediato de algunas áreas de la geografía espanola va a estar gravemente marcado por el despoblamiento y el acusado envejecimiento de su población.

Por otra parte, desde una perspectiva general, hay que tener en cuenta que el proceso de transición demográfica en su conjunto tampoco se ha dado de manera uniforme y homogénea en todo el país. Así, los datos de los estudios de los demógrafos, permiten comprobar diferencias sustanciales entre las distintas regiones y provincias españolas, especialmente entre aquellas en las que tiene un peso mayor la población rural o la urbana ${ }^{9}$. En cualquier caso, en lo que se refiere al conjunto nacional, y de cara a un futuro inmediato, la tendencia hacia la homogeneización de las características demográficas parece irreversible en un contexto general ya más claramente situable en las coordenadas de lo que se conoce como modelo de evolución demográfica moderna.

No obstante, hay que ser conscientes de que el hecho de que en España determinadas pautas de natalidad, mortalidad y nupcialidad hayan empezado a producirse según patrones propios de las sociedades urbano-industriales occidentales en un período de tiempo reciente, que coincide precisamente con el proceso de democratización, no debe hacernos perder de vista que en su conjunto el perfil de la población española presenta - debido aún a

-Véanse Juan DfEz NicorÁs, "La transición demográfica en España", op. cit., pp. 89 y ss.; Salustiano del Campo, Análisis de la población de España, op. cit., pp. 81 y ss.; Amando de MIGUEL, La pirámide social española, Barcelona, Ariel, 1977, pp. 105 y ss., y Alfonso G. Barbancho, Población, empleo y paro, Madrid, Pirámide, pp. 49 y ss. 
las recientes inercias del pasado- diversas singularidades y características propias, hasta el punto de constituir, como ha subrayado Nadal, un cierto modelo «de transición demográfica de características intermedias entre la de los países más avanzados y la de los países más atrasados... En medio de estos dos tipos de evolución - dirá Nadal- la evolución española resulta atípica. Aquí, por lo que empieza a vislumbrarse, el crecimiento de población no habrá sido ni tan duradero como en la mayor parte de los estados europeos, ni tan intenso como en los estados del tercer mundo. Sin dejar de producirse en el curso del siglo xIx, el desarrollo de la población española se ha acelerado en el $\mathrm{xx}$ en virtud de un rápido descenso de la mortalidad, llegado no obstante cuando la mortalidad ya se hallaba en neta regresión. A juzgar por los datos... la plétora demográfica habría tenido un duración de sesenta años, de 1921 a $1980{ }^{10}$. De hecho, precisamente, en las décadas de los años 60 y 70 en las que se produce con más intensidad un proceso de crecimiento económico, sin una paralela modernización social y política, se dan los mayores incrementos del volumen de población de España (un 111 por mil en cada década en comparación, por ejemplo, con un crecimiento de un 66 por mil habitantes previsto para la década de los 80 y unos crecimientos de un 81 y un 87 por mil, respectivamente, para las décadas de los años 40 y 50 ). Sin embargo, es evidente que en las próximas décadas la caída de las tasas de nupcialidad y de natalidad van a traducir un aumento mucho más bajo de la población, habiéndose hecho, por ejemplo, previsiones de un crecimiento de un 35 por mil para la década de los años $90^{11}$.

La comparación de las pirámides de población correspondientes a los Censos de 1900, 1970 y 1981 que podemos ver en el gráfico 1 nos ilustra claramente sobre esta evolución, que tiende, como ya señalamos, a dibujar un perfil diferente entre dichas pirámides.

Ciertamente, no se puede desconocer la importancia de las consecuencias económicas, sociales - y hasta políticas- de la nueva situación demográfica. Las nuevas pautas de configuración de la población van a afectar de manera muy importante el futuro económico de muchas regiones españolas, en donde lo que ha ocurrido, ha llegado a ser calificado por algunos demógrafos como «verdaderos cataclismos demográficos» ${ }^{12}$. Igualmente van a tener una incidencia tremenda sobre el sistema económico global y sobre el mismo sistema de Seguridad Social, en la medida en que la «población jubilada» cada vez va a representar una proporción mayor (lo cual resulta más importante en un país como España que, debido a la incidencia del paro y de la escasa incor-

to Jordi Nadal, La población española (siglos XVI a XX), Barcelona, Ariel, 1984, pp. 262-263. 1981.

"INE, Proyección de la población española para el período 1978-1995, Madrid,

12 Alfonso G. Barbancho, Población, empleo y paro, op. cit., p. 58. 
poración de la mujer al trabajo, tiene una de las tasas de población activa ocupada más baja de Europa).

Si a esto añadimos la manera en que la evolución de la población va a afectar a la distribución espacial de la oferta y la demanda de servicios, a las necesidades del sistema educativo, y a la misma oferta de fuerza de trabajo, comprenderemos hasta qué punto resulta importante tanto una rigurosa previsión de las actuales tendencias de evolución de la población, como una adecuada planificación de las medidas necesarias para hacer frente a los diversos problemas de ajuste que van a plantearse a medio y largo plazo.

\section{GRAFICO 1}

Evolución del perfil de la pirámide de población de España de 1900 a 1970 y 1981

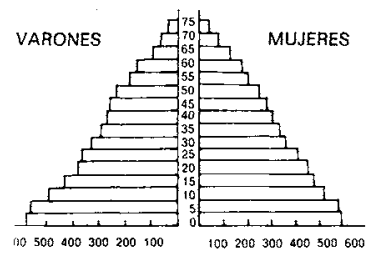

AÑO 1900

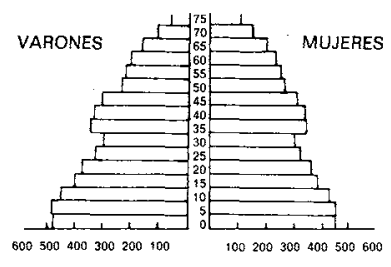

AÑO 1970

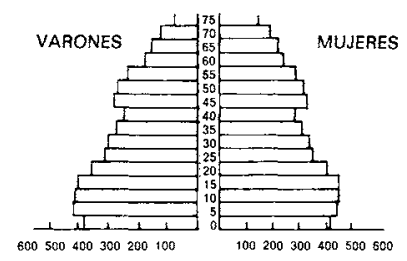

AÑO 1981

\section{Los movimientos migratorios}

\section{Las migraciones exteriores}

A lo largo del siglo xx se han producido en España importantes procesos de emigración exterior. En los años anteriores a la guerra civil las corrientes migratorias se dirigieron fundamentalmente hacia los países de ultramar. Sin embargo, con posterioridad a 1939 este flujo va a ir decreciendo progresivamente. Así, en 1950 se registran 55.314 emigraciones a países de ultramar, disminuyendo esta cifra a 34.328 en 1969 , a 25.825 en 1963 y a 19.258 en 1967 , siendo de 6.009 en 1972 , de 3.372 en 1970 , de 4.180 en 1979 , de 5.787 en 1981 y de 3.345 en 1983. De una manera paralela al descenso de la emigración a ultramar se van a ir produciendo importantes flujos de emigración a los países europeos, hasta alcanzar una especial intensidad en la década de los 60 y primeros años de la de los 70. En concreto, las cifras oficiales recogerán en el período que va de 1960 a 1973 un total de 2.341.004 personas que cruzaron nuestra frontera en búsqueda de trabajo en los países europeos. De estas personas casi la mitad lo hicieron en concepto de emigrantes permanentes, y el resto como emigrantes de tempo. 
rada ${ }^{13}$. A partir de 1974 la evolución de la situación económica mundial dará lugar a una importante reducción del número de emigrantes. Así, el Instituto Español de Emigración dará unas cifras de 50.695 emigrantes estables a los países europeos para $1974,20.618$ para 1975 y sólo 12.124 para 1976. A partir de 1976 la tendencia es ya claramente mayoritaria de retorno, siendo el saldo neto de retornos de 1976 a 1981 de 270.000 personas.

Sin embargo, estos datos, con ser bastante reveladores, no nos permiten tener una imagen exacta de lo que ha representado el fenómeno de la emigración en la España de nuestro tiempo, y ello no sólo por la imprecisión que supone la evolución conjunta de una emigración de temporada, en la que realmente hay, año tras año, bastantes coincidencias en las personas, sino también por el hecho de que una gran parte de la emigración española se va a producir de una manera extraoficial (cruzando las fronteras como turistas), sin que quede constancia alguna en las estadísticas oficiales. Por ello, los datos que han proporcionado algunos países europeos sobre el flujo de emigraciones españolas en su suelo, no han coincidido generalmente con las estadísticas españolas ${ }^{14}$.

En el inicio de la década de los 70 el Instituto Nacional de Emigración va a dar unas cifras que permiten estimar el volumen total de españoles que en aquel momento residian fuera de nuestras fronteras por motivos de trabajo en cerca de tres millones y medio de personas, de los cuales un 65 por 100 se encontraban afincados en países americanos. Si tenemos en cuenta que, según datos del Censo de población de 1970, la población ocupada no llegaba en dicho momento a los 12 millones de personas, podemos hacernos una idea de lo que tal volumen de emigrantes significó realmente en la dinámica social española.

Ciertamente, la emigración a ultramar presentó unas características muy distintas de los procesos migratorios a los países europeos que se van a producir con especial intensidad, como hemos dicho, en los años de la década de los 60. La emigración a ultramar obedece generalmente a planteamientos distintos y se realiza con objetivos también diferentes. Incluso en su procedencia regional hay apreciables diferencias entre los que emigraron a los países de ultramar (gallegos, asturianos, cántabros, canarios, catalanes, etc.) y los emigrantes a Europa (andaluces, gallegos, extremeños, etc.) ${ }^{15}$.

13 Fuente: Instituto Nacional de Estadfstica, España. Panorámica social, op. cit., 1974, p. 65.

${ }_{14}$ Un ejemplo de las diferencias de las estadísticas españolas con los tres países europeos que han recibido un mayor volumen de emigrantes españoles (Alemania, Francia y Suiza) puede verse en el Informe FOESSA 1975, Madrid, Euramérica, 1976, p. 63.

${ }^{15}$ Realmente las emigraciones hacia Europa afectaron a los naturales de casi todas las regiones españolas, pero, sin embargo, los núcleos mayoritarios del origen de estos procesos migratorios no coinciden completamente con los que se orientaron hacia los países de ultramar. Sobre el tema de la emigración pueden consultarse, entre otros, los siguientes trabajos: Jesús Garcf́ Fernández, La emi- 
El trabajador emigrante a Europa generalmente no se planteaba unos objetivos tan ambiciosos como muchos de los emigrantes a ultramar, ni tampoco una duración tan dilatada de su estancia exterior. Mientras que la emigración a ultramar supuso un mayor grado de afincamiento y generalmente cubría todo un ciclo vital, la emigración a Europa fue, para la mayor parte de los que «pasaron» por ella, una forma de cubrir unos objetivos económicos a corto plazo y solucionar unas necesidades inmediatas. La mayor parte de los emigrantes a Europa se vieron forzados a la emigración por imperiosas razones económicas y vivieron en sus países de destino con grandes estrecheces y realizando el máximo esfuerzo de trabajo y ahorro, pensando en volver cuanto antes a España.

Los mayores volúmenes de población emigrante española se encuentran localizados en Argentina, que absorbe más de la mitad de la emigración a ultramar, existiendo también importantes colonias de residentes españoles en Brasil, Venezuela y México.

En Europa el mayor flujo migratorio se produjo hacia Francia, que puede calcularse que absorbió más de la mitad del total de población española emigrante en el continente, seguida por Alemania, Suiza y Bélgica. En el caso de Francia, ciertamente, los datos de la emigración laboral se superpusieron a los de una importante emigración política, que tuvo también una apreciable influencia sobre la primera. En cualquier caso puede decirse que en su conjunto la población española emigrante, al desenvolverse en contextos sociales y políticos tan diferentes de los de la España franquista, tuvo una experiencia que trascendiendo al plano de su trabajo permitió la difusión de mentalidades políticas y sindicales que ejercieron una considerable influencia politizadora. Lo cual fue, también, un factor estimulador del cambio social y político.

Ciertamente esta experiencia de la emigración, que como hemos visto ha venido afectando a tantos millones de españoles, ha sido, sin duda alguna, uno de los fenómenos sociológicos más importantes de la España de nuestro tiempo. Fenómeno que ha tenido su cara y su cruz, en lo que ha supuesto tanto para la dinámica del proceso de crecimiento económico, como en lo que ha significado para esos millones de personas. En tal sentido no hay que olvidar que la emigración ha sido una poderosa válvula de escape para los

gración exterior de España, Barcelona, Ariel, 1965; Angel PAScual, El retorno de los emigrantes, ¿conflicto o integración?, Barcelona, Nova Terra, 1969; Francisco SÁNChez LóPEz, Emigración española a Europa, Madrid, Confederación Española de Cajas de Ahorro, 1969; J. A. Garmendi, Alemania: exilio del emigrante, Barcelona, Plaza y Janés, 1970; L. A. Martinez Cachero, La emigración española a examen, Madrid, ASE, 1970; Guillermo L. Díaz-PLAJA, La condición de emigrante, Madrid, Edicusa, 1974; Javier RuBio, La emigración española a Francia, Barcelona, 1974; Campos NordmaNN, La emigración española y el crecimiento económico español, Madrid, Instituto Español de Emigración, 1976; José A. GarmenDIA (ed.), La emigración española en la encrucijada. Marco general de la emigración de retorno, Madrid, CIS, 1981, y José Castillo Castillo, La emigración española en la encrucijada. Estudio empírico de la emigración de retorno, Madrid, CIS, 1981. 
desajustes del sistema económico español, en el que no existía un puesto de trabajo para cada español, aliviando así el volumen global del paro. A su vez, la emigración dio lugar a la entrada en España de un flujo permanente de divisas - las famosas «remesas de los emigrantes»-, que permitieron ir enjugando una parte de los saldos negativos de la deficitaria balanza comercial. En contraste con la importancia de este papel de la emigración, a efectos de determinada política económica, sobre todo durante la etapa de mayor crecimiento económico, el trabajador español en Europa se encontró con gran cantidad de problemas de todo tipo (familiares, de residencia, de comunicación, de adaptación y convivencia), que convirtieron esta «experiencia» para muchos en una experiencia bastante penosa, sin contar las más de las veces con una efectiva política de apoyo y ayuda por parte de las autoridades españolas. Para muchos emigrantes, a su vez, el colofón de su «experiencia» ha sido el «retorno» en un contexto de crisis económica y crecimiento del paro, que ha acabado haciendo cada vez más difíciles las posibilidades de encontrar trabajo en su propio país.

\section{Las migraciones interiores: Urbanización y éxodo rural}

Si importantes han sido en la España de este siglo los movimientos migratorios hacia el exterior, mucho más importantes aún han sido los movimientos migratorios interiores. Desde principios de siglo la progresiva disolución de las estructuras de la sociedad tradicional ha dado lugar a un fenomenal proceso de cambio social, que ha supuesto, entre otras cosas, el desplazamiento de grandes masas de millones de personas por toda nuestra geografía. Así los datos censales sobre saldos de emigrantes netos por partidos judiciales han permitido dar unas cifras de $\ll 10.868 .725$ españoles que desde 1900 a 1970 han abandonado su municipio de origen, pero que probablemente - se nos dirá- en la realidad hayan pasado de los 14 millones» ${ }^{16}$. De una manera más concreta, en el período comprendido entre los censos de 1960 y 1970 nada menos que 4.473 .000 personas abandonaron sus municipios de origen, siendo 4.180 .371 los que han cambiado de municipio de residencia desde 1971 a $1982^{17}$.

Obviamente unos desplazamientos de población de tales magnitudes suponen una importante conmoción para toda la estructura social. Sin embargo, son dos los fenómenos específicamente asociados a tan intensos procesos migratorios interiores: en primer lugar, el despoblamiento no sólo de determinadas áreas de la geografía española, sino, más concretamente, de las áreas

16 Informe FOESSA 1975, op. cit., p. 68. La razón por la que se estima superior la cifra de emigrantes interiores reales es porque los datos referidos a partidos judiciales no recogen los posibles desplazamientos de población desde los municipios más pequeños hacia los municipios cabezas de partido judicial.

${ }^{17} \mathrm{INE}$, Anuarios estadísticos, 1972-1984. 
y núcleos de población rurales, de una forma y con una intensidad tal que se ha generalizado el uso de la bíblica expresión de «éxodo rural» para referirse a este fenómeno social. Ciertamente el «éxodo rural» tiene una dimensión más directamente económica, que se traduce en la misma composición de la estructura de la población activa, pero también tiene una dimensión poblacional en cuanto afecta a la misma evolución de la distribución de la población española en diferentes tipos de hábitats, con todas las consecuencias sociológicas y hasta políticas que ello implica. $\mathrm{Y}$ también en distintos tipos de regiones y áreas de la geografía española. Los datos correspondientes a los saldos migratorios de las distintas regiones demuestran, tal como podemos ver en la tabla 3, que hasta 1975 las pautas de emigración e inmigración perfilan claramente a determinadas regiones como fuertemente receptoras de inmigrantes: Cataluña, Madrid, Valencia, País Vasco, en tanto que regiones como Andalucía, Extremadura, Galicia, Murcia y las dos Castillas han tenido fuertes saldos migratorios negativos, especialmente durante la década de los años 60 y la primera mitad de la de los 70 . Sin embargo, a partir de la segunda mitad de la década de los 70 parecen empezar a dibujarse nuevas orientaciones en los movimientos migratorios. Así, Madrid y Valencia son las únicas regiones que continúan recibiendo inmigrantes en

TABLA 3

Saldos migratorios regionales en España de 1960 a 1982

\begin{tabular}{|c|c|c|c|c|}
\hline & $1960-1970$ & $1971-1975$ & $\begin{array}{c}1976-\text { marzo } \\
1981\end{array}$ & 1982 \\
\hline Andalucía $\ldots \ldots \ldots \ldots$ & -843.767 & -294.210 & -8.895 & 5.742 \\
\hline $\begin{array}{llllll}\text { Aragón } & \ldots & \ldots & \ldots & \ldots & \ldots\end{array}$ & -34.352 & -32.335 & 12.103 & 362 \\
\hline $\begin{array}{llllll}\text { Asturias } & \ldots & \ldots & \ldots & \ldots & \ldots\end{array}$ & 31.345 & 1.980 & 4.702 & 370 \\
\hline $\begin{array}{llllll}\text { Baleares } & \ldots & \ldots & \ldots & \ldots & \ldots\end{array}$ & 73.713 & 30.999 & 39.639 & 2.395 \\
\hline $\begin{array}{llllll}\text { Canarias } & \ldots & \ldots & \ldots & \ldots & \ldots\end{array}$ & 19.420 & 62.639 & -14.339 & 2.459 \\
\hline 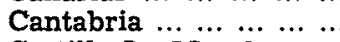 & 14.485 & $-\quad 3.425$ & 3.364 & 503 \\
\hline Castilla-La Mancha .. .. & -458.432 & -143.348 & -36.483 & 443 \\
\hline Castilla-León .......... & -399.633 & -202.177 & -26.465 & 1.203 \\
\hline $\begin{array}{llllll}\text { Cataluña } & \ldots & \ldots & \ldots & \ldots & \ldots\end{array}$ & 719.966 & 198.855 & 84.262 & -16.096 \\
\hline Extremadura ........... & -378.165 & -134.013 & -37.837 & 2.677 \\
\hline $\begin{array}{ccccc}\text { Galicia } & \ldots & \ldots & \ldots & \ldots\end{array} \ldots$ & -229.167 & -38.753 & -361 & 405 \\
\hline $\begin{array}{llllll}\text { Madrid } \ldots & \ldots & \ldots & \ldots & \ldots & \ldots\end{array}$ & 686.554 & 209.216 & 116.419 & 966 \\
\hline Murcia $\ldots \ldots \ldots \ldots \ldots$ & -101.651 & -17.789 & 22.811 & 1.863 \\
\hline 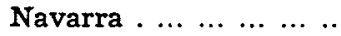 & 18.510 & $-\quad 5.215$ & 8.292 & 651 \\
\hline $\begin{array}{llllll}\text { Valencia } & \ldots & \ldots & \ldots & \ldots & . .\end{array}$ & 302.666 & 128.810 & 113.627 & 1.874 \\
\hline 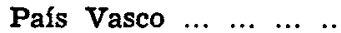 & 256.098 & 59.760 & -17.563 & 6.435 \\
\hline $\begin{array}{llllllll}\text { Rioja } & \ldots & \ldots & \ldots & \ldots & \ldots & . .\end{array}$ & 12.544 & $-\quad 2.785$ & 6.129 & 1.005 \\
\hline
\end{tabular}

Fuentes: INE, Censo de la Población de España 1970, Madrid, 1974; Las migraciones interiores en España, Madrid, 1974; La población de España. Censo 1981, Madrid, 1983; Anuario Estadístico 1984 (elaboración propia). 
cantidades importantes, aunque mucho menores que durante la década de los 60, mientras que las corrientes migratorias hacia Cataluña y el País Vasco se han visto frenadas, incluso con saldos negativos en 1982 en el caso de Cataluña, y más acusadamente a partir de 1976 en el caso del País Vasco. Simultáneamente Murcia pasa de ser una región de emigrantes a recibir un significado flujo de inmigración, al igual que ocurre en Aragón, al tiempo que Andalucía, Galicia, Extremadura y las dos Castillas ven disminuidas sus pérdidas de población emigrante durante la segunda mitad de la década de los 70 , e incluso presentan saldos positivos o casi equilibrados durante el último año del que se dispone de datos en el momento en que esto se escribe (1982).

Si a esto añadimos que los movimientos de cambio de municipio de residencia han continuado siendo importantes también durante los últimos años - como podemos constatar en los datos de la tabla 4-, comprenderemos hasta qué punto los movimientos migratorios interiores en España han adquirido una nueva significación a partir de la segunda mitad de la década de los 70. A juzgar por los datos disponibles hasta el momento, los principales rasgos que definen la nueva situación son los siguientes:

a) Reducción de los flujos de emigración procedentes de las regiones

\section{TABLA 4}

Migraciones interiores de 1971 a 1982 y su distribución según municipios de procedencia

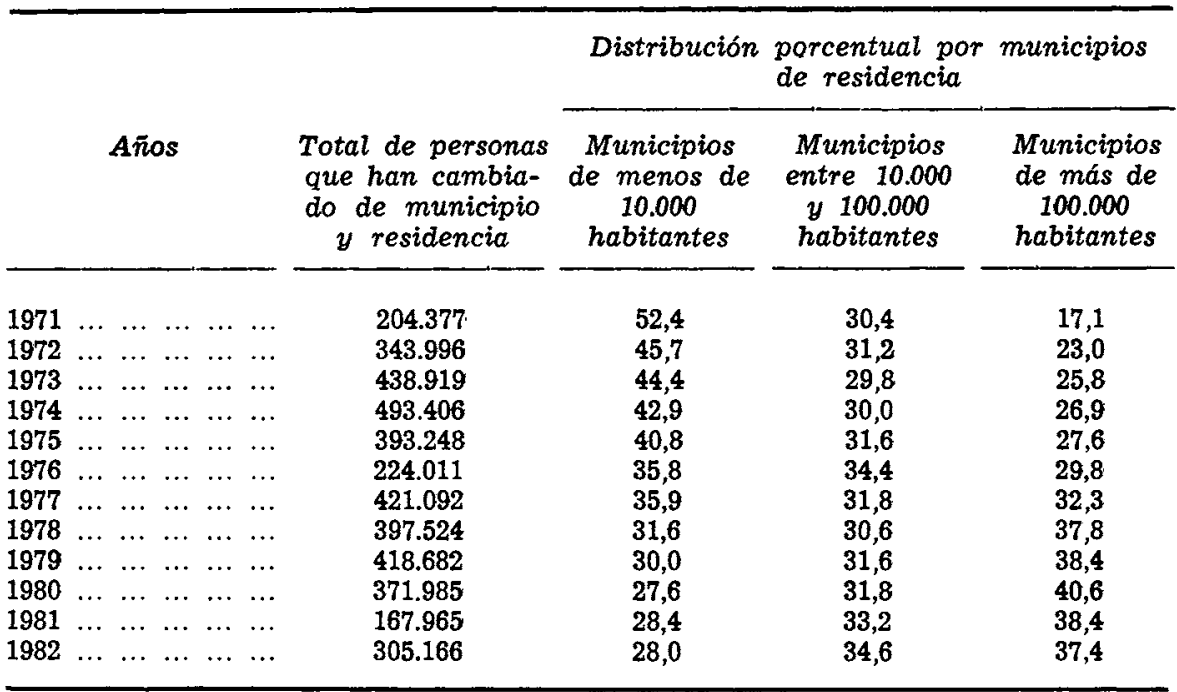

FuENTE: INE, Anuarios Estadísticos, años 1972 a 1984 (elaboración propia). 
tradicionalmente más infradesarrolladas, con tendencia incluso a la estabilización.

b) Reducción de la capacidad de atracción de población de Cataluña y el País Vasco, con saldos migratorios negativos durante los últimos años.

c) Mantenimiento de unos niveles altos de movilidad geográfica, con un mayor peso, lógicamente, de los movimientos migratorios intraprovinciales e intrarregionales.

d) Mayor complejidad y diversidad reciente de los movimientos migratorios según tamaño de municipios de residencia, con una reducción del volumen global de movilidad de población procedente de municipios de menos de 10.000 habitantes y un aumento paralelo de la movilidad geográfica de la población residente en los municipios de más de 100.000 habitantes. Este fenómeno, que resulta especialmente perceptible también a partir de 1975 (vid. tabla 4), obviamente tiende a cambiar y matizar el específico significado de «éxodo rural» que habían tenido los movimientos migratorios en España durante la década de los 60 y la primera mitad de la de los 70 .

En resumen, puede decirse que los intensos movimientos migratorios que se continúan produciendo en España tienden a presentar perfiles menos acusados de éxodo rural y de despoblamiento de las regiones más infradesarrolladas, para adquirir unos significados de procesos de movilidad geográficos más complejos y diversificados, en los que es posible identificar también movimientos de movilidad desde los municipios de tamaño intermedio a los más grandes, y desde estos últimos hacia otros municipios del mismo tamaño, e incluso hacia municipios intermedios y pequeños.

Por otra parte, respecto a la forma y al ritmo que se ha producido el proceso de urbanización en España, debe tenerse en cuenta que a principios de siglo vivía en municipios de menos de 10.000 habitantes un 67,8 por 100 de la población, mientras que en 1981, tal como podemos ver en la tabla 5 , vivía en este tipo de municipios un 26,8 por 100 , en tanto que desde principios de siglo las proporciones de los residentes en municipios de más de 10.000 habitantes habían pasado de ser un 32,2 por 100 a un 73,2 por 100 en 1981, con un 42 por 100 de la población total residiendo en municipios de más de 100.000 habitantes.

Como podemos ver, los crecimientos más importantes de población se van a producir en los municipios de más de 100.000 habitantes, que precisamente van a pasar a ser seis a principios de siglo, a ser 18 en 1940, 24 en 1950,38 en 1970 y 50 en 1981 , mientras que los municipios de menos de 100 habitantes, por ejemplo, como consecuencia de los procesos de despoblamiento, pasan de ser 19 a princnipios de siglo, a ser 451 en 1970 y 682 en $1981^{18}$. .

18 Instituto Nacional de Estadística, Anuario Estadístico 1977, p. 37, y Anuario Estadístico 1982, p. 39. 


\section{TABLA 5}

Distribución de la población según el tamaño y características de los municipios

\begin{tabular}{|c|c|c|c|c|c|c|}
\hline & Censos & $\begin{array}{c}\text { Municipios } \\
\text { hasta } \\
2.000 \text { hab. } \\
\%\end{array}$ & $\begin{array}{c}\text { Municipios } \\
\text { de } 2.001 a \\
10.000 \text { hab. } \\
\%\end{array}$ & $\begin{array}{c}\text { Municipios } \\
\text { de } 10.001 \text { a } \\
100.000 \text { hab. } \\
\%\end{array}$ & $\begin{array}{c}\text { Municipios } \\
\text { de más de } \\
100.000 \text { hab. } \\
\%\end{array}$ & $\begin{array}{c}\text { Población } \\
\text { residente en } \\
\text { las capitales } \\
\text { de provincia } \\
\%\end{array}$ \\
\hline 1900 & $\begin{array}{llllll}\ldots & \ldots & \ldots & \ldots & \ldots\end{array}$ & 27,5 & 40,3 & 23,2 & 9,0 & 16,8 \\
\hline 1910 & $\begin{array}{llllll}\ldots & \ldots & \ldots & \ldots & \ldots\end{array}$ & 25,5 & 39,5 & 24,7 & 10,3 & 17,4 \\
\hline 1920 & $\begin{array}{lllll}\ldots & \ldots & \ldots & \ldots & \ldots\end{array}$ & 23,2 & 38,1 & 26,7 & 12,0 & 19,1 \\
\hline 1930 & $\begin{array}{llllll}\ldots & \ldots & \ldots & \ldots & \ldots\end{array}$ & 20,5 & 36,6 & 28,0 & 14,8 & 21,6 \\
\hline 1940 & $\begin{array}{lllll}\ldots & \ldots & \ldots & \ldots & \ldots\end{array}$ & 18,4 & 32,8 & 29,7 & 19,1 & 24,4 \\
\hline 1950 & $\begin{array}{llllll}\ldots & \ldots & \ldots & \ldots & \ldots\end{array}$ & 16,7 & 31,2 & 28,1 & 24,0 & 27,5 \\
\hline 1960 & $\begin{array}{lllll}\ldots & \ldots & \ldots & \ldots & \ldots\end{array}$ & 14,5 & 28,7 & 29,0 & 27,7 & 30,8 \\
\hline 1970 & $\begin{array}{llllll}\ldots & \ldots & \ldots & \ldots & \ldots\end{array}$ & 11,0 & 22,5 & 29,7 & 36,8 & 35,7 \\
\hline 1981 & $\begin{array}{lllll}\ldots & \ldots & \ldots & \ldots & \ldots\end{array}$ & 8,6 & 18,2 & 31,2 & 42,0 & 36,9 \\
\hline
\end{tabular}

Fuentes: Instituto Nacional de Estadística, España. Panorámica social 1974, op, cit, p. 57, e INE, Censo de 1981, op. cit.

La drástica reducción de población en núcleos rurales y la paralela tendencia a una creciente urbanización forman parte, obviamente, de un proceso de cambio y transformación social más global, pudiendo hablarse de un verdadero tránsito desde un tipo de sociedad rural estamental a una sociedad urbano-industrial, que implica un conjunto bastante amplio de cambios sociales, culturales y políticos de todo tipo. En este sentido no hay que olvidar que la palabra «urbanización» tiene un cierto doble significado: por una parte, hace referencia a un fenómeno de concentración espacial de la población, pero, por otra parte, se asocia a la idea de difusión de un determinado tipo de cultura urbana, que es precisamente la cultura que va a generalizarse, en la medida en la que la «revolución burguesa» - y no olvidemos que burgués viene de «burgo», significando literalmente habitante de ciudad-, logra afirmar ideológica y políticamente su propio modelo de sociedad y cultura de manera global, es decir, más allá de su espacio propio; afirmación que no denota de esta manera sino la propia hegemonía de la ciudad en los nuevos sistemas sociales.

Incluso, hay que tener en cuenta que la ciudad se afirma como forma de vida, también en nuestro país, más allá de la incidencia de determinadas variables económicas, como el mismo nivel de industrialización alcanzado. Esta dinámica propia de las ciudades como núcleos administrativos y de servicios explica, por ejemplo, que en determinadas áreas agrícolas de España, de manera paralela al éxodo hacia otras zonas industrializadas del país, se haya producido un significativo proceso de concentración de población en 
determinados núcleos urbanos intermedios. Como ha subrayado Rodríguez Osuna, la «resistencia de las capitales de las provincias agrícolas a despoblarse y su continuado crecimiento, incluso en los años de crecimiento y desarrollo de las áreas industriales», se puede explicar por la mejor dotación de infraestructuras de todo tipo, la centralización de toda clase de servicios y el hecho de que, en varias provincias, sea la capital el único núcleo de población relativamente importante. Es así —concluirá Rodríguez Osunacómo las capitales, independientemente de su menor o mayor desarrollo industrial, se configuran como núcleos de servicios para una vasta población, eminentemente rural, dispersa en multitud de municipios de escaso tamaño» ${ }^{19}$.

Por todo ello puede decirse que el proceso de urbanización no sólo tiene la significación de que España haya dejado de ser «estadísticamente» un país «eminentemente rural», sino que supone un cambio más general en los modos de poblamiento, que permite, entre otras cosas, el desarrollo de las bases para la difusión de las nuevas mentalidades y planteamientos sociopolíticos propios del modelo social urbano-industrial.

Respecto a la forma en que se ha producido el proceso de urbanización en España, hay que tener en cuenta que la experiencia ha demostrado que los procesos de urbanización se producen conforme a unas ciertas orientaciones que perfilan sistemas de jerarquización y especialización funcional que suponen, entre otras cosas, que la tendencia a la atracción de población (y a la prestación de servicios) es mayor en determinadas ciudades que se convierten de facto en líderes del sistema urbano - Londres en Inglaterra, París en Francia, Nueva York en Estados Unidos, etc.-, a la vez que otras ciudades tienden a especializarse en el desempeño de determinadas funciones socioeconómicas.

En el caso concreto de nuestro país, el proceso de urbanización se ha producido de una manera en la que ha quedado patente que España - como ha señalado Díez Nicolás-, en cuanto «sistema social relativamente autárquico y autosuficiente, ha surgido de la agregación de una serie de subsistemas regionales, cada uno de los cuales era, a su vez, en materia de sustento, relativamente autárquico y autosuficiente. Esto es lo que podría explicar, probablemente - dirá Díez Nicolás - el que hasta 1930 no hubiese gran diferencia entre Madrid y Barcelona, mientras que a partir de 1940 la diferencia entre ambas se va haciendo paulatinamente mayor. El anterior bicefalismo, o multicefalismo, podría atribuirse a una falta real de interdependencia entre las distintas regiones españolas, mientras que la actual tendencia hacia el monocefalismo podría indicar asimismo una tendencia hacia la completa integración e interdependencia (en materia de sustento) de las regiones españolas. En resumen —concluirá Díez Nicolás-, todos los datos parecen llevar

19 Jacinto Rodríauez Osuna, "Desequilibrios espaciales en la España de los siglos $\mathrm{xIx}$ y $\mathrm{xx}$ ", Revista Española de Investigaciones Sociológicas, núm. 23, Madrid, julio-septiembre 1983, p. 29. 
a las mismas conclusiones: a) que España ha pasado de ser un conjunto de regiones relativamente autárquicas y autosuficientes a ser (o estar en vías de ser) un sistema social de regiones interdependientes en materia de sustento; b) que como consecuencia, la ciudad de mayor tamaño (Madrid) no ha alcanzado la población que parece debería tener para convertirse en cabeza dominante de este sistema social integrado mediante la interdependencia ecológica, $y / o c$ ) que no existe suficiente desarrollo de las ciudades grandes intermedias» ${ }^{20}$.

Los últimos datos disponibles, sin embargo, ponen de relieve que la tendencia al crecimiento de Madrid —y más específicamente de su área metropolitana en conjunto- ha alterado algunas de las apreciaciones anteriores sobre este tema.

De hecho la población residente en unas pocas ciudades, tiende a convertirse en el núcleo poblacional mayoritario de España, habiendo podido hacerse previsiones para 1990 de acuerdo con las cuales el 62 por 100 del total de población vivirá en sólo 13 ciudades, concentrando solamente Madrid y Barcelona el 31 por 100 del total de población española ${ }^{21}$.

No obstante, los datos del censo de población de 1981 revelan que sólo cuatro capitales - aparte de Madrid y Barcelona- superan la cifra del medio millón de habitantes (Valencia, Sevilla, Zaragoza y Málaga), estando por encima de los 400.000 Bilbao, y concentrándose en estas siete ciudades españolas el 20,7 por 100 de la población ${ }^{22}$. Obviamente el reducido número de este tipo de ciudades intermedias - como señaló Díez Nicolás-, tiene importantes efectos en todo nuestro sistema urbano. Efectos que últimamente empiezan a manifestar nuevos perfiles importantes, en tanto en cuanto el crecimiento y la atracción de población ya no se produce sólo en el perímetro de los municipios de Madrid y Barcelona, sino también - y de manera muy importante- en torno a sus áreas metropolitanas. Así, el enorme crecimiento de las «ciudades-dormitorio» próximas a los municipios de Madrid y Barcelona dan una nueva dimensión a la cuestión, al tiempo que revelan la inadecuación de los criterios clasificatorios tradicionales y formales, así como el desfase de las actuales soluciones organizativo-administrativas para el tratamiento de las nuevas realidades sociológicas poblacionales. Es evidente que desde un punto de vista real las poblaciones actuales de Madrid y Barcelona, por ejemplo, no están integradas sólo por los que localizan su domicilio en el perímetro «oficial» del término municipial, sino que se extienden a todos los que habitan en sus cada vez más amplias áreas metropolitanas.

En tal sentido, hay que tener en cuenta que, según datos del padrón mu-

20 Juan Díez Nicolás, Especialización funcional y dominación en la España urbana, Madrid, Guadarrama, 1973, pp. 114-115.

${ }^{21}$ Véase Luis RAcionero Gran, "Sistemas urbanos y desarrollo descentralizado", en Estudios Regionales, Madrid, Instituto Nacional de Prospectiva y Desarrollo Económico, 1976, p. 220.

22 INE, Censo de población de 1981, op. cit. 
nicipal de habitantes de 31 de marzo de 1983, las 11 ciudades de más de 50.000 habitantes próximas a Barcelona concentraban una población de 1.459.928 habitantes, teniendo a su vez un total de 1.098 .360 habitantes los 10 grandes municipios cercanos a Madrid. Si a estas poblaciones unimos las correspondientes a otros municipios menores de 50.000 habitantes, que realmente forman parte del «espacio» de las dos grandes ciudades españolas, podemos constatar que virtualmente en 1983 residían en las áreas metropolitanas de Madrid y Barcelona cerca del 22 por 100 del total de la población española.

Resulta importante destacar, en este sentido, que en el último período intercensal (1970-1981), el crecimiento de las dos grandes ciudades no se ha producido realmente en el ámbito formal de sus respectivos perímetros municipales, sino en su espacio metropolitano. Así, por ejemplo, entre 1970 y 1981 la población municipal de Barcelona sólo creció en un 0,6 por 100, mientras que los 11 grandes municipios de su entorno crecieron en un 30,6 por 100. Asimismo, en ese mismo período la población residente en el municipio de Madrid llegó a decrecer en un 0,7 por 100 , en tanto que la población de los 10 grandes municipios de su entorno ;creció nada menos que en un 245 por 100! Lo que revela no sólo que Madrid crece realmente a través de sus «ciudades-dormitorio», sino también que la mayor capacidad de atracción de población del «área metropolitana de Madrid» tiende a reforzar de facto su situación de liderazgo en el sistema urbano.

Sin embargo, si en vez de utilizar criterios más específicos de «cercanía» para delimitar los espacios metropolitanos empleamos criterios jurídico-formales, nos encontraremos con que entonces las «áreas metropolitanas» españolas concentran una población mucho mayor, habiendo llegado a ser estimada para 1985 solamente en el caso de las «áreas» de Madrid y Barcelona en más de doce millones y medio de personas ${ }^{23}$. En cualquier caso, aunque la dispersión geográfica de los municipios «incluidos» en algunas «áreas metropolitanas» sea en algunos casos bastante grande, lo cierto es que la evolución reciente de los parámetros correspondientes a población y a superficie metropolitana reflejan claramente el grado de concentración metropolitana de la población que se está produciendo en España, tal como podemos ver en el gráfico 2.

Ciertamente el crecimiento acelerado de las ciudades, y especialmente la conformación de grandes áreas metropolitanas, implica un conjunto muy diverso de problemas de adaptación y ajuste a las nuevas necesidades de prestación de servicios urbanos y de ordenación del mismo espacio urbano. En el caso de España la falta de una adecuada planificación del crecimiento urbano y la forma en que se produjo éste en los años de más fuerte crecimiento económico, ha dado lugar a importantes problemas, cuyas consecuencias se

${ }^{23}$ Alfonso de Esteban, Las áreas metropolitanas en España. Un análisis ecológico, Madrid, Centro de Investigaciones Sociológicas, 1981, p. 102. 
irán aún manifestando progresivamente. En gran parte el crecimiento de las ciudades, y especialmentte el de las áreas metropolitanas, ha sido bastante caótico y desordenado, y precisamente como reacción frente a los nuevos problemas dimanantes de tal proceso de urbanización han surgido con pujanza, durante los últimos años, un nuevo tipo de movimientos sociopolíticos: los movimientos urbanos (asociaciones de vecinos, de consumidores, de defensores del equilibrio ecológico, etc.), que nuclean sus actividades principalmente en torno a objetivos orientados a la autodefensa contra las múltiples agresiones urbanas que sufren los habitantes de las ciudades como consecuencia tanto del acelerado proceso de urbanización como, especialmente, de la forma en que éste se ha producido.

\section{GRAFICO 2}

Relación entre población y superficie metropolitana $y$ su evolución
Población
metropolitana

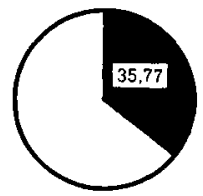

1960
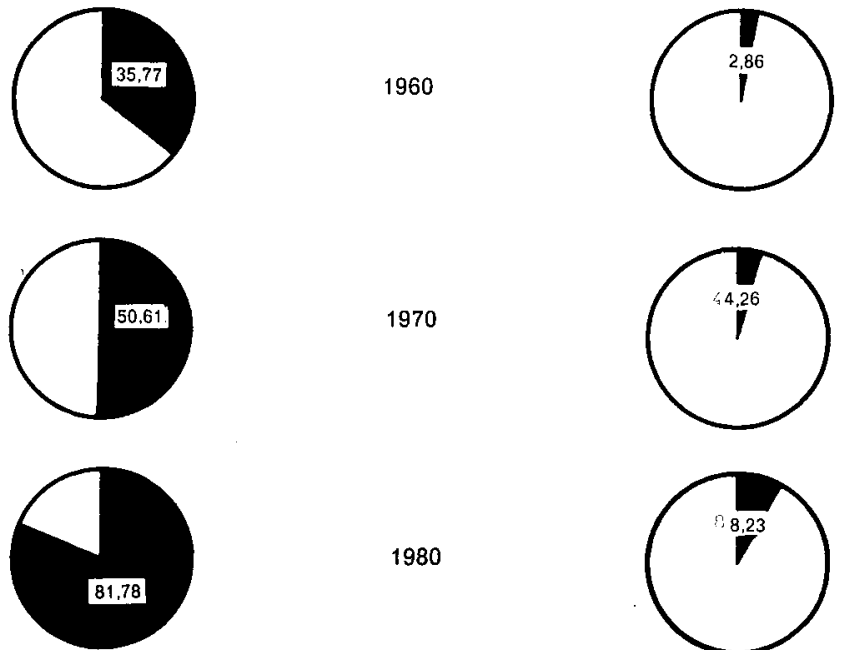

1970

1980

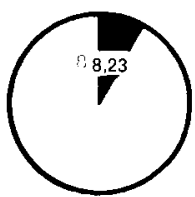

Fuente: Alfonso de Esteban, Las áreas metropolitanas españolas, op. cit., pp. 88 y 89 .

3. Transformaciones en la estructura de clases

Sin duda alguna, el más importante cambio que se ha producido en la estructura social de España en los últimos años de nuestra historia, ha sido la transformación en la estructura de clases. España ha pasado de tener una estructura de clases típica de una sociedad rural, semiestamental y semiindustrializada, a tener una estructura de clases típica de una sociedad indus- 
trial. Precisamente al análisis de estas transformaciones he dedicado un buen número de estudios ${ }^{24}$. Basta, pues, señalar aquí que estas transformaciones han supuesto, entre otros, tres cambios fundamentales.

En primer lugar, la pérdida de peso del mundo campesino en nuestra estructura de clases, como consecuencia tanto de las drásticas reducciones de la población activa agrícola, como de las alteraciones del peso específico de los distintos sectores laborales en el conjunto de la estructura de clases campesinas. La población activa campesina ha pasado de ser casi la mitad de nuestra población activa después de la guerra civil, a ser un 14,4 por 100 , según datos del censo de 1981. En concreto, los obreros agrícolas han quedado reducidos a un 5 por 100 del total de la población activa (vid tabla 6), habiěndose producido también importantes disminuciones en el número de propietarios agrícolas.

En segundo lugar, una transformación importante en la estructura de clases ha sido el desarrollo de la clase obrera en su conjunto y su nuevo perfil social. Por primera vez en la historia de España, y como consecuencia del proceso de industrialización, existe una clase obrera industrial numerosa y prácticamente repartida por toda la geografía nacional. Pero la clase obrera industrial en la España actual ya no es la clase obrera propia de un sistema capitalista tradicional, sino que presenta rasgos propios de las sociedades industriales avanzadas. Así es clara la tendencia a una cada vez mayor cualificación de los trabajadores manuales, mientras que los peones sin cualificar disminuyen tanto en números absolutos como relativos. A su vez esta tendencia a una mayor cualificación de la clase trabajadora tiene una nueva dimensión en tanto en cuanto se están produciendo importantes crecimientos en los sectores más altamente cualificados de la población activa industrial: técnicos, ingenieros, profesionales, etc. $\mathrm{Y}$ todo ello supone una diversificación de la clase trabajadora en su conjunto -incluso hay quienes prefieren hablar, más propiamente, de «clases trabajadoras»- que no es sino una consecuencia del paso de un tipo de sociedad de capitalismo tradicional a un nuevo tipo de sociedad industrial avanzada. En tal sentido un conjunto de factores diversos -entre los que los tecnológicos han jugado un papel clave- están dando lugar a ciertos grados de estratificación de la clase trabajadora industrial. Así, la complejidad de los sistemas de producción dan lugar a diferentes niveles de cualificación y formación entre los trabajadores que, a su vez, dan lugar a diferentes niveles salariales, que, asimismo, se traducen en diferentes estilos y niveles de vida entre los diversos grupos de asalariados, con todo lo que ello implica.

El tercer gran cambio en la estructura de clases es el crecimiento del personal administrativo, comercial y técnico - lo que se ha dado en llamar

${ }^{24}$ Véanse, entre otros, Las nuevas clases medias, Madrid, Edicusa, 1973; Estructura de clases $y$ conflictos de poder en la España postfranquista, Madrid, Edicusa, 1978; ¿Crisis de la conciencia obrera?, Madrid, Mezquita, 1982; Sociología del socialismo español, Madrid, Tecnos, 1983. 
las «nuevas clases medias»-, que ha llegado a representar un 22,2 por 100 del total de la población activa, siendo uno de los sectores que ha experimentado un más rápido crecimiento en los últimos años, hasta un punto tal que si en los próximos años se mantiene un ritmo similar de crecimiento, antes de que termine la década de los 80 el personal administrativo, comercial y técnico representará un cuarto del total de población activa y más de un tercio del total de población asalariada. De hecho, todos los datos hacen prever que este sector va a continuar creciendo, tal como ha sucedido en los países más industrializados hasta llegar a representar más de un 30 por 100 del total de la población activa.

\section{TABLA 6}

\section{Estructura de la población activa ocupada en 1984}

\begin{tabular}{|c|c|c|c|c|}
\hline \multirow{2}{*}{\multicolumn{2}{|c|}{ 1. BLOQUE DE CLASES PROPIETARIAS: }} & Número & \multicolumn{2}{|c|}{$\%$} \\
\hline & & & & \\
\hline 1.1. & Sector empresarial capitalista: & & & \\
\hline & 1.1.1. Empresarios agrarios con asalariados $\ldots$ & 30.400 & $0,3)$ & \\
\hline & $\begin{array}{l}\text { 1.1.2. Empresarios con asalariados de la indus- } \\
\text { tria y los servicios } \ldots \ldots \\
\ldots\end{array}$ & 273.100 & 2,6 & 4,8 \\
\hline & 1.1.3. Gerentes y directores $\ldots \ldots \ldots c c c c c$ & 204.900 & $1,9)$ & \\
\hline 1.2 . & Sector de autopatronos e independientes: & & & \\
\hline & 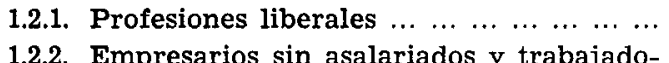 & 107.400 & $1,0)$ & \\
\hline & $\begin{array}{l}\text { 1.2.2. Empresarıos sin asalariados } \mathrm{y} \text { trabajado- } \\
\text { res independientes } \ldots \ldots \\
\ldots\end{array}$ & 1.345 .400 & 12,7 & 26,2 \\
\hline & 1.2.3. Propietarios agrícolas sin asalariados ... & 1.312 .900 & 12,5 & \\
\hline
\end{tabular}

2. Bloque DE clases asalariadas:

2.1. Trabajadores no manuales $y$ de servicios:

2.1.1. Personal administrativo, comercial y téc$\begin{array}{lllllllllllll}\text { nico } & \ldots & \ldots & \ldots & \ldots & \ldots & \ldots & \ldots & \ldots & \ldots & \ldots & \ldots & \ldots\end{array}$

2.1.2. Contramaestres y capataces $\ldots . \ldots, \ldots$ 2.344 .600 85.300

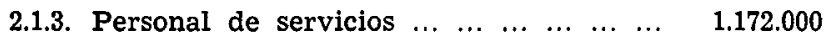
$\left.\begin{array}{r}22,2 \\ 0,8 \\ 11,1\end{array}\right\} 34,1$

2.2. Obreros:

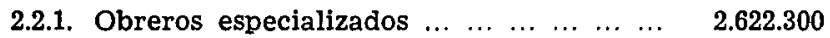

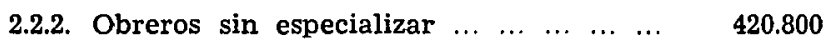

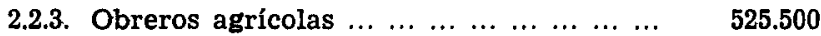

3. OTRos *

120.000

FuenTE: INE, Encuesta de población activa, primer trimestre de 1984, Madrid, 1984 (elaboración propia).

* Incluye 82.400 profesionales de las Fuerzas Armadas. 
$Y$ junto a lo anterior, toda una serie de cambios diversos, no por menores menos importantes, refuerzan los significados de estas transformaciones: así, la pérdida de peso de las viejas clases medias, que viven una especial situación de crisis, el nuevo papel de los profesionales y los técnicos, que han pasado de ser un 3,3 por 100 en 1950 a un 9,7 por 100 en 1981 (vid tabla 7), la persistencia de importantes sectores de trabajadores autónomos y de pequeños comerciantes y propietarios, los aumentos de los trabajadores del sector servicios, e incluso la emergencia de nuevas profesiones de alta cualificación dentro de este sector -economistas, sociólogos, publicistas, expertos en marketing y comunicaciones, etc.-, que han llevado a algunos a hablar de un nuevo sector «cuaternario», etc.

\section{TABLA 7}

Evolución de los distintos sectores ocupacionales de la población activa, según los censos de población de 1950, 1960, 1970 y 1981

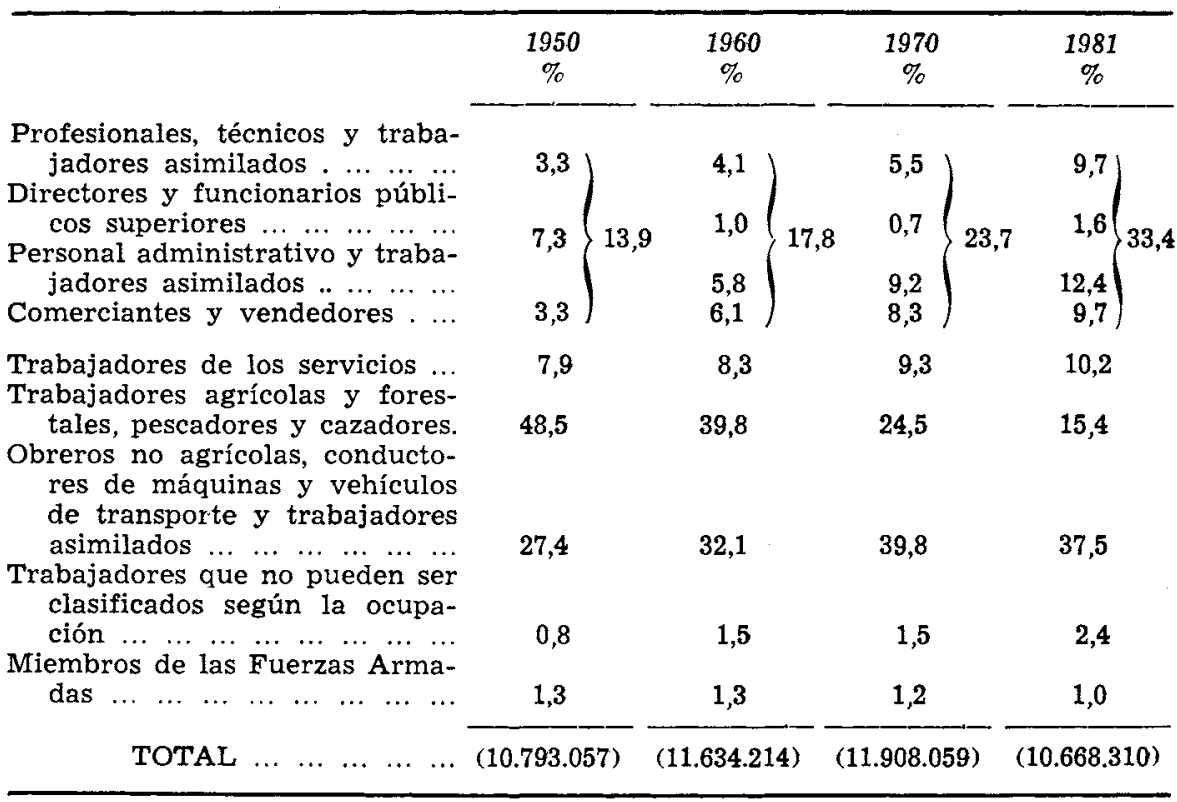

Fuentes: INE, Censos de población de España 1950, 1960 y 1970, y Avance de Resultados de 1981 (elaboración propia).

En resumen, puede decirse que la evolución de la estructura de clases española, permite trazar la hipótesis de un progresivo afianzamiento de los sectores ocupacionales de «nueva clase media» (técnicos y profesionales, ofi- 
cinistas, vendedores, etc.), que corre paralelo a un persistente peso de ciertos sectores de «viejas clases medias» agrícolas y comerciantes, y de autónomos $\mathrm{y}$ de pequeños industriales, que pese a sufrir un claro proceso de deterioro económico y de encontrarse con crecientes dificultades objetivas para «competir» en las nuevas situaciones del mercado español, continúan constituyendo en 1984 un núcleo importante de la población ocupada (cercano a los tres millones de activos). A su vez la clase obrera manual de la industria representa en su conjunto un sector ocupacional decreciente, especialmente en lo que se refiere a los obreros sin especializar, que han disminuido en un 63,6 por 100 desde 1965, tal como podemos ver en los datos de la tabla 8. Lo cual debe ser contemplado en relación al hecho de que la población activa

\section{TABLA 8}

Evolución de los sectores ocupacionales de la población activa de 1965 a 1984

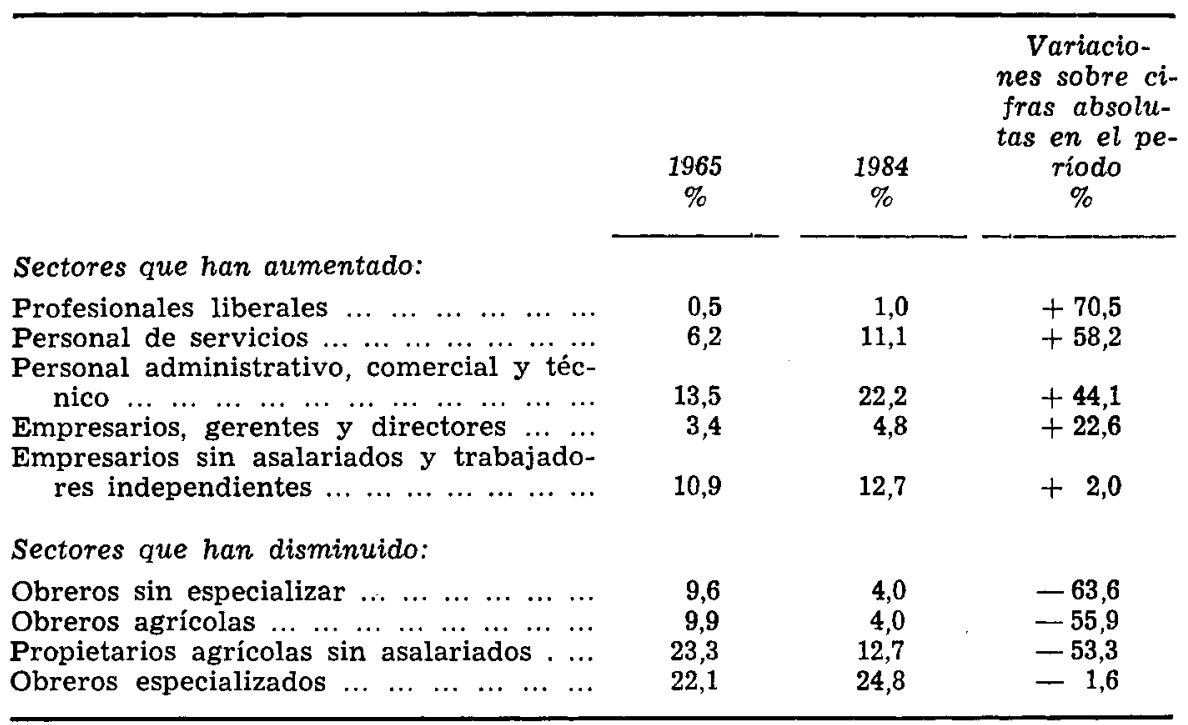

FUENTE: INE, Encuestas de población activa (elaboración propia).

industrial española ha pasado de ser el 37 por 100 a mediados de la década de los 70, a un 33,5 por 100 en 1984, en tanto que la población activa del sector servicios, en el mismo período, ha pasado de ser un 39 por 100 a más de un 45 por 100 . En su conjunto, pues, la dinámica evolutiva de determinados sectores ocupacionales - tal como puede ser apreciada en los datos de las tablas 7 y 8 -, y el mismo proceso general de «terciarización» del sistema económico español, a lo que apunta claramente es a una situación en la que 
la «clase obrera manual» se configura como un sector más - no necesariamente mayoritario - entre el conjunto de los asalariados, e incluso podríamos decir con más rigor entre el conjunto de las «clases trabajadoras».

\section{Consumismo y sociedad de consumo}

Para los teóricos del desarrollismo la dinámica socioeconómica conduce a etapas de desarrollo económico caracterizadas por la disposición generalizada de todo tipo de bienes de consumo. Así, para Rostow las últimas fases de su modelo de evolución económico de las sociedades serán conceptualizadas, precisamente, en función del consumo - «La era del alto consumo de masas» y «Más allá del consumo»-y serán descritas como la consecuencia de la orientación de los recursos hacia la «producción de bienes duraderos de consumo y a la difusión de servicios en gran escala», una vez que la mayoría de población sobrepasa el nivel de satisfacción de las necesidades básicas («habitación, vestido y sustento») ${ }^{25}$.

La difusión en la práctica del nuevo tipo de sociedad de consumo ha dado lugar a un conjunto muy amplio y variado de análisis sobre los supuestos y consecuencias del nuevo períado de evolución de las sociedades. Así los enfoques más economicistas, que veían la sociedad de consumo fundamentalmente como una etapa más de procesos histórico-económicos más dilatados, pronto fueron completados con teorías que ponían un mayor énfasis en la psicología del consumidor - y en su «soberanía»- como elemento fundamental de la nueva realidad ${ }^{26}$. Sin embargo, la sociedad de consumo, obviamente, no se desarrolla solamente como una consecuencia de las mayores disponibilidades de renta y mayores capacidades de producción, ni tampoco por la mera predisposición "psicológica» al consumo. En tal sentido, tiene razón Ernest Zahn al señalar que el consumo -como el trabajo- «no son sólo conceptos económicos, sino también sociológicos y culturales» ${ }^{27}$. De hecho una abundante investigación empírica ha demostrado cómo los comportamientos del consumidor están básicamente condicionados por factores sociales ${ }^{28}$. El consumidor, ciertamente, no es como algunos parecen pensar, un sujeto individual sin voluntad, al que la publicidad pueda obligar sin más a consumir lo que a los productores y comerciantes se les antoje, sino que el consumidor decide su nivel de consumo en función de los datos de su situación

${ }^{25}$ W. W. Rostow, Las etapas del crecimiento económico, México, F.C.E., 1965, p. 23.

${ }_{26}$ Así, por ejemplo, George Katona, La sociedad de consumo de masas, Madrid, Rialp, 1968.

${ }^{27}$ Ernest ZaHN, Sociología del desarrollo económico, Barcelona, Sagitario, 1963, p. 37 .

${ }^{28}$ En España contamos, sobre este tema, con una importante investigación empírica de J. C. Castillo, La sociedad de consumo. Consideraciones sobre la racionalidad y libertad del consumidor español, Madrid, Escuela de Organización Industrial, 1968. 
económica y también -y no como lo menos importante- en función de las pautas de consumo socialmente imperantes. Muchas veces el ciudadano de las sociedades industrializadas de nuestro tiempo se ve socialmente compelido al consumo de ciertos bienes, no porque realmente los necesite para vivir, sino porque su uso se ha generalizado hasta tal punto que el no poseerlos se constituye en un hecho atípico o extravagante, e incluso socialmente sancionado ${ }^{29}$.

$\mathrm{Ni}$ qué decir tiene que las consecuencias que el desarrollo de la sociedad de consumo tiene en el orden sociopolítico quizás no hayan sido aún descubiertas en su totalidad, pese a que una copiosa literatura sobre el tema ha intentado analizar los múltiples efectos sociales del desarrollo de un modelo de «sociedad de consumo». Así la dinámica «consumista» ha sido puesta en relación, por ejemplo, con la apatía sociopolítica, con la mayor o menor «integración en el sistema», con el desarrollo de orientaciones de «retraimiento individualista», con el «conservadurismo» político, etc. En cualquier caso, más allá de las conclusiones a que se pueda llegar, es evidente que se trata de un fenómeno sociológico importante, cuyas consecuencias políticas no se deben minusvalorar.

De todo lo anterior, pues, se desprende que para evaluar el grado en que una sociedad se encuentra inserta en la lógica de la sociedad de consumo, hay que tener en cuenta, no sólo los datos económicos básicos del problema (grado de industrialización y desarrollo, niveles de renta y riqueza, etc.), sino también los datos sociales y culturales del mismo (distribución de las rentas, grado de difusión de las mentalidades típicas de la sociedad de consumo, presión social hacia el consumo, etc.). A partir de la consideración de estos datos es cuando estamos en condiciones de preguntarnos, en rigor, hasta qué punto la dinámica de la sociedad española puede considerarse plenamente como una dinámica de sociedad de consumo.

Hasta hace muy poco tiempo, el mismo volumen de las rentas medias de nuestro país, así como las enormes desigualdades personales y regionales en su distribución, junto a la escasa difusión de los más típicos bienes de consumo, dio lugar a una percepción de los hechos que, como señalaba José Castillo en un artículo publicado en 1966, llevaba a considerar que nuestro país no se encontraba «aún en la etapa del consumo de masas»: sólo algunas clases sociales en ciertas zonas geográficas gozan de «discrecionalidad» de

29 Por ello, dando la vuelta a la teoría de Veblen, se ha llegado a hablar de un tipo de consumo anti-ostentario: el que se realiza para mantenerse al nivel medio existente y no quedar marcado por ninguna diferencia - por exceso o por defecto- que pudiera suponer pérdida de prestigio e integración y consideración social. Véanse, por ejemplo, las consideraciones sobre este tema que hace Murillo Ferrol en su prólogo al libro de Ernest ZaHN, Sociología del desarrollo económico, op. cit., p. 18. Véase igualmente William H. WhYTE, El hombre organización, México, F.C.E., 1968, pp. 295-313, en donde se desarrolla con algún detalle esta teoría del consumo no ostentatario, o no conspicuo, que hace del grupo social el elemento fundamental a la hora de "determinar cuándo un lujo se convierte en una necesidad" (p. 297). 
conducta... Son muchos los españoles — señalaba Castillo- que todavía se enfrentan con el problema diario de la subsistencia. La pobreza existe en nuestro país y no limitada a un pequeño grupo de españoles. Para éstos, la alimentación, el vestido, la vivienda, en su expresión más elemental, ocupan acuciantemente todos sus desvelos» ${ }^{30}$.

Obviamente, en nuestros días esta percepción de los hechos se ha modificado sustancialmente, como consecuencia tanto del crecimiento económico, como de la ampliación del número de ciudadanos con unas rentas medias idóneas para el «consumismo», como por la evolución en el reparto de gastos en los presupuestos familiares, y también -claro está- como consecuencia del aumento de la producción de bienes de consumo y la paralela difusión de su tenencia y disfrute. $Y$ también - y no como lo menos importante-, por la fuerte y creciente socialización de la población en los hábitos consumistas ${ }^{31}$.

En primer lugar, el incremento de la renta media por habitante ha sido bastante considerable, especialmente en los últimos años. Así, hemos pasado de una renta per cápita de 9.800 pesetas en 1955 a 34.983 pesetas en 1965 , a 156.070 en 1975 y a 468.060 pesetas en 1982 . O, para dar los datos en una medida que, pese a la continua inflación, conserva un cierto valor comparativo internacionalmente, España ha pasado de tener una renta per cápita de 290 dólares en 1960, de 497 en 1964 y de 2.486 dólares en 1975, a tener en 1981 una renta de 4.432 dólares por habitante ${ }^{32}$. Lo cual, sin duda,

30 José Castillo Castillo, "¿Es España sociedad de consumo de masas?", Anales de Sociología, núm. 1, 1966, p. 18. Algún tiempo después Manuel Navarro, manejando datos de consumo hasta 1968, coincidirá básicamente en la misma apreciación, señalando ya cómo el consumo en España es "el de una economía a medio camino en el desarrollo económico" (Manuel Navarro, "Pautas de consumo en España y diferencias regionales", en La España de los años setenta, tomo I, Madrid, La Sociedad, Moneda y Crédito, 1972, p. 816).

${ }^{31}$ El mismo Castillo, en un artículo reciente, subrayará hasta qué punto la población española fue "socializada anticipadamente" por la RTVE y las películas americanas en determinadas pautas de consumo y hasta qué punto los niños y jóvenes españoles actuales se encuentran plenamente inmersos en los hábitos consumistas modernos: "Nuestros hijos y nietos - dirá Castillo- se zambullen de buenas a primeras, y como la cosa más natural del mundo, en la esfera de los cacharros electrónicos. No es un espécimen raro el niño que no necesita de la abuela para que le cuente cuentos; de la madre para que le enseñe canciones; del padre para que le haga las cuentas; del hermano para que juegue con él, porque para todo esto y otras muchas cosas dispone del correspondiente ingenio electrónico. Además, es que no hay comparación posible: ninguno de los seres de carne y hueso con los que a diario convive el niño pueden competir con las máquinas, que se saben todos los cuentos imaginables, que cantan canciones modernas, que no se equivocan en las cuentas y que no se cansan de jugar, y que, por si faltara algo, para conseguir lo que se espera de ellas basta con apretar un botón" (José Castillo Castillo, "Los hijos de la sociedad de consumo española", REIS, núm. 17, enero-marzo 1982, p. 51.

${ }^{32}$ Fuentes: Contabilidad nacional y Anuarios Estadisticos, varios años. Otras fuentes - por ejemplo, los estudios del Banco de Bilbao- dan cifras que presentan muy ligeras diferencias con éstos. 
en un contexto internacional sitúa a España entre los países que tienen una renta per cápita media (vid gráfico 3).

Por otra parte, las encuestas de presupuestos familiares revelan, como podemos ver en la tabla 9, que los gastos de alimentación, vestido y calzado representan una cuota cada vez menor en el presupuesto medio familiar, al tiempo que cada vez es mayor el porcentaje del presupuesto destinado a gastos diversos y vacaciones. En su conjunto, lo que estos datos significan es que cada vez es menor la parte del presupuesto familiar destinada a cubrir los gastos imprescindibles de subsistencia, quedando, por tanto, disponibles unos remanentes monetarios que pueden dedicarse, entre otras posibles cosas, a la adquisición de bienes de consumo.

\section{GRAFICO 3}

Renta por babitante en 1981 en diversos paises

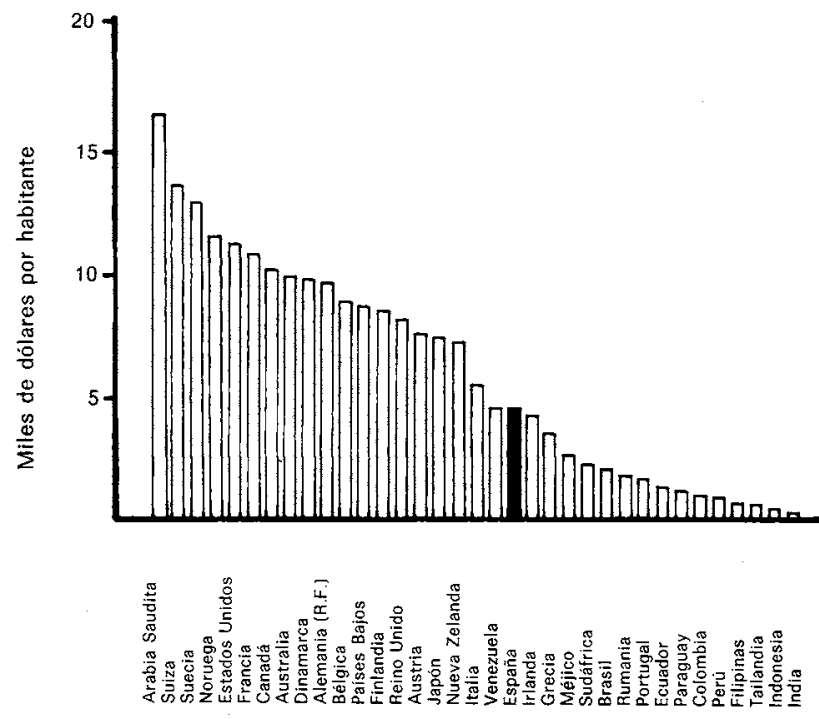

Fuente: Anuario Banesto del mercado español, Madrid, 1984, p. 207

Por supuesto, la estructura del consumo, así como el volumen global del gasto medio, varían mucho de unas regiones a otras, y también presentan notables diferencias, en general, entre el medio rural y el urbano. Así, mientras que en los núcleos urbanos el porcentaje del consumo total anual dedicado a alimentación, vestido y calzado representaba en 1973-1974 un 41,8 por 100 del gasto total, en los núcleos no urbanos representaba el 50,5 por 
100, siendo de un 36,1 por 100 en 1980-1981 en los núcleos urbanos y de un 43,3 por 100 en los no urbanos ${ }^{33}$.

\section{TABLA 9}

\section{Evolución de la estructura del presupuesto de consumo medio por persona}

\begin{tabular}{|c|c|c|c|c|c|c|}
\hline & 1958 & 1964 & 1966 & 1968 & $1973-74$ & $1980-81$ \\
\hline $\begin{array}{llllll}\text { Alimentación } & \ldots & \ldots & \ldots & \ldots & \ldots\end{array}$ & 55,3 & 48,6 & 44,7 & 44,4 & 38,0 & 30,7 \\
\hline Vestido y calzado .............. & 13,6 & 14.9 & 13,5 & 13,5 & 77 & 85 \\
\hline $\begin{array}{lllllllll} & \text { Vivienda } & \ldots & \ldots & \ldots & \ldots & \ldots & \ldots & \ldots\end{array}$ & 5,0 & 7,4 & 10,5 & 10,3 & 12,0 & 15,4 \\
\hline 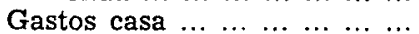 & 8,3 & 9,2 & 8.6 & 8,1 & 10.7 & 10,0 \\
\hline Gastos diversos y vacaciones. & 17,8 & 19,9 & 22,7 & 23,7 & 31,6 & 35,4 \\
\hline
\end{tabular}

Fuente: Encuestas de presupuestos familiares.

Las nuevas disponibilidades de renta, que son una consecuencia tanto de su incremento global como de las modificaciones en la orientación de los presupuestos familiares, son - como hemos dicho- los prerrequisitos para un incremento de la producción y compra de los más típicos bienes de consumo. En este sentido los datos de la tabla 10 nos dan una idea clara de cómo han ido aumentando en los últimos años las unidades producidas en un conjunto de bienes de consumo. Especialmente significativo resulta, por la influencia decisiva que tiene en todo el sistema productivo, el incremento de la producción de automóviles de turismo, hasta un punto de que se ha pasado de tener 108.023 automóviles en circulación en 1955, a tener 652.297 en $1964,1.052 .506$ en $1966,2.377 .7266$ en 1970 y 4.806 .833 en 1975 , experimentándose cierta disminución en el número de automóviles matriculados por año a partir de 1977 , con 654.033 turismos matriculados en 1978 , 620.652 en $1979,574.149$ en 1980 y 505.716 en 1981 , produciéndose una cierta tendencia al alza en el número de turismos matriculados nuevamente en los años 1982 (535.733) y 1983 (550.436). Las cifras menores de matriculación correspondientes a estos años lógicamente traducen también un cierto grado de «densificación» del parque de vehículos en circulación, ya que, por ejemplo, mientras que en el año 1975, como hemos visto, había menos de 5 millones de automóviles en circulación, en 1981 había 7.943.225, alcanzando la cifra de 8.714 .076 en $1983^{34}$.

${ }^{33}$ FUENTE: Encuesta de presupuestos familiares, op. cit., p. 270.

${ }^{34}$ A estos vehículos hay que añadir, en 1981, 1.257.138 motocicletas y 1.396.809 camiones, $y$ en 1983, 1.310.037 motocicletas y 1.529.081 camiones Fuente: INE, Anuarios Estadísticos, varios años. 
TABLA 10

Evolución de la producción de varios bienes de consumo en España.

(Unidades)

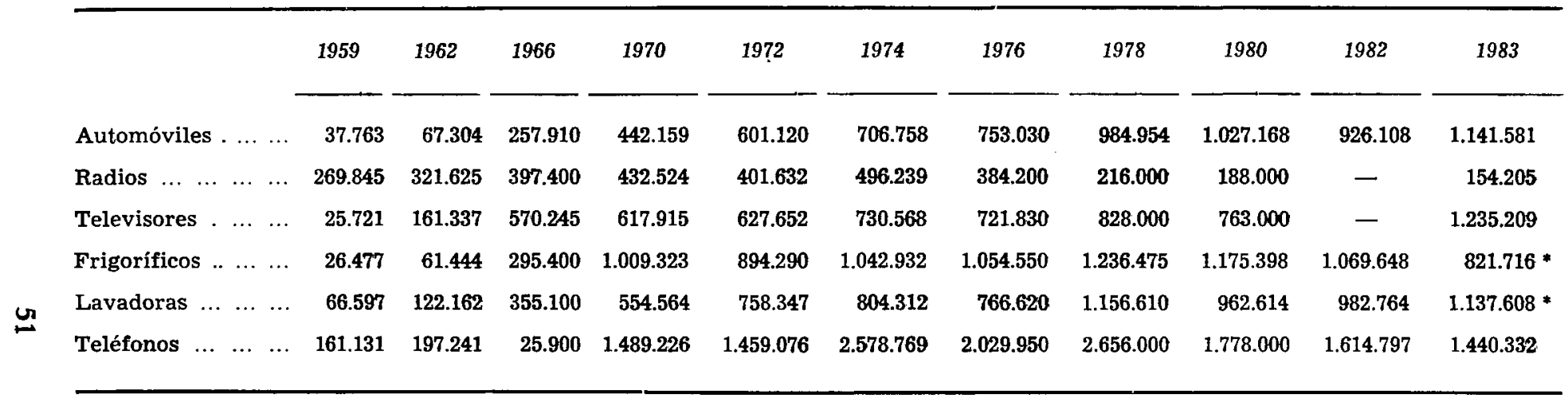

Fuentes: Instituto Nacional de Estadfstica, Anuarios Estadísticos, varios años; INE, Encuesta Industrial años 1978 a 1981 , Madrid, 1984, y Organizaciones Patronales (elaboración propia).

* A falta de los datos del último trimestre. 
Igualmente diversas encuestas permiten constatar cómo ha ido evolucionando la posesión de diferentes bienes en los hogares españoles, tal como podemos ver en los datos de la tabla 11.

Tanto si tenemos en cuenta los datos de las encuestas FOESSA, como los del Instituto Nacional de Estadística, nos encontramos con que en un lapso de unos siete años (1966-68 a 1973-75), prácticamente se duplicaron los niveles de posesión de algunos de los más típicos bienes de consumo, habiéndose producido también unos incrementos especialmente notables en el período de 1975 a $1980-81$.

Del conjunto de datos hasta aquí manejados puede deducirse, en consecuencia, que en estos momentos sí puede afirmarse que España presenta las características de una sociedad de consumo de masas, a pesar de que los niveles de renta y consumo españoles tienen aún notables diferencias con los de los países más industrializados. Sin embargo, no es ésta la objeción más importante que puede hacerse para una completa homologación de las condiciones de España con las típicas de una sociedad de consumo de masas, sino más bien la forma en que las características propias de la sociedad de consumo no se producen en áreas y regiones muy concretas. En este sentido, la persistencia de grandes desigualdades da lugar a que determinados niveles de consumo no se hayan convertido aún en España en completamente masivos.

Así, los datos de la tabla 12 nos permiten comprobar, por ejemplo, cómo entre las regiones con mayor nivel de consumo y aquellas en la que éste es menor, se producen diferencias muy apreciables en las proporciones de hogares en los que se poseen determinados bienes de consumo ${ }^{35}$.

Igualmente las diferencias en los niveles de posesión de bienes de consumo son muy notables según el tamaño de los municipios, pudiendo decirse que existe un claro escalonamiento en los grados de posesión, desde los municipios de menos de 10.000 habitantes (con un 42,5 por 100 de hogares con automóviles, un 13 por 100 con televisiones en color y un 45,4 por 100 con lavadora automática y un 2 por 100 con lavavajillas), a los comprendidos entre 10.001 a 50.000 habitantes (con un 51,3 por 100 con automóvil, un 24,1 por 100 con televisión en color, un 62,7 con lavadora automática y un 4,1 por 100 con lavavajillas), a los de 50.001 a 500.000 (57 por 100 , 32,3 por $100,74,6$ por 100 y 7,5 por 100 , respectivamente), hasta los municipios de más de 500.000 habitantes, que son en los que existen unos mayores niveles de posesión de todos estos bienes $(57,2$ por 100 para automó-

${ }^{35}$ En 1980-1981, las regiones con el menor nivel de consumo son prácticamente las mismas que en 1975 , pero sin embargo se han producido algunas modificaciones en el grupo de las regiones con mayor nivel de consumo. Así, por ejemplo, el País Vasco ha pasado del segundo lugar en 1975, después de Cataluña, a un sexto o séptimo lugar en 1980-1981, incluso por detrás de Murcia, en lo que hace a posesión de automóviles y aparatos de televisión en color. 


\section{TABLA 11}

Evolución de la posesión de algunos bienes de consumo por bogar, según varias fuentes $y$ años

\begin{tabular}{|c|c|c|c|c|c|c|}
\hline & $\begin{array}{c}\text { Encuesta } \\
\text { FOESSA I } \\
(1966)\end{array}$ & $\begin{array}{c}\text { Encuesta } \\
\text { Equipamiento } \\
\text { INE (1968) }\end{array}$ & $\begin{array}{c}\text { Encuesta } \\
\text { Cajas de } \\
\text { Ahorro (1968) }\end{array}$ & $\begin{array}{c}\text { Encuesta } \\
\text { FOESSA III } \\
(1973)\end{array}$ & $\begin{array}{c}\text { Encuesta } \\
\text { Equipamiento } \\
\text { INE (1975) }\end{array}$ & $\begin{array}{c}\text { Encuesta } \\
\text { Equipamiento } \\
\text { INE } \\
(1980-1981)\end{array}$ \\
\hline $\begin{array}{llllllll}\text { Frigorífico } & \ldots & \ldots & \ldots & \ldots & \ldots & \ldots & \ldots\end{array}$ & 28 & 35 & 41 & 82 & 74 & 91 \\
\hline $\begin{array}{llllllll}\text { Televisión } & \ldots & \ldots & \ldots & \ldots & \ldots & \ldots & \ldots\end{array}$ & 32 & 38 & 48 & 85 & 79 & $72 / 26 *$ \\
\hline $\begin{array}{lllllllll}\text { Lavadora } & \ldots & \ldots & \ldots & \ldots & \ldots & \ldots & \ldots & \ldots\end{array}$ & 36 & 39 & 47 & 71 & 60 & 80 \\
\hline 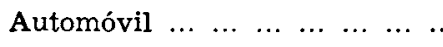 & 12 & 13 & 16 & 38 & 34 & 52 \\
\hline $\begin{array}{llllllll}\text { Tocadiscos } & \ldots & \ldots & \ldots & \ldots & \ldots & \ldots & \end{array}$ & 12 & 8 & - & 35 & 19 & 20 \\
\hline & 2.456 & 60.791 & 4.457 & 4.347 & 55.448 & 24.000 \\
\hline
\end{tabular}

* Televisión en blanco y negro, 72 por 100, y televisión en color, 26,5 por 100.

FUENTES: Informe FOESSA I, Euramérica, Madrid, 1966, p. 75. INE, Encuesta de equipamiento y nivel cultural de la familia 1968, Madrid, 1968, vol. I, pp. 123-124. Data, Comportamientos y actitudes de las economías domésticas hacia el ahorro y el consumo, Madrid, Confederación Española de Cajas de Ahorro, 1968, p. 207. Informe Foessa III, Madrid, Euramérica, 1976, p. 975. INE, Encuesta de equipamientos y nivel cultural de las familias 1975, Madrid, 1976, vol. I, pp. 86-87. INE, Encuesta de presupuestos familiares 1980-1981, Madrid, 1983, tomo II, pp. 212-214. 
viles, 40,8 por 100 para televisores en color, 79,3 por 100 para lavadoras automáticas y 13,4 por 100 para lavavajillas) ${ }^{36}$.

TABLA 12

Diferentes niveles interregionales de posesión de determinados bienes de consumo, 1980-1981

\begin{tabular}{|c|c|c|c|c|}
\hline & Automóvil & $\begin{array}{l}\text { Televisión } \\
\text { color }\end{array}$ & $\begin{array}{l}\text { Lavadora } \\
\text { automática }\end{array}$ & $\begin{array}{l}\text { Lava- } \\
\text { vajillas }\end{array}$ \\
\hline \multicolumn{5}{|l|}{$\begin{array}{l}\text { Regiones con mayor nivel de } \\
\text { consumo: }\end{array}$} \\
\hline $\begin{array}{lllllllll}\text { Navarra } & \ldots & \ldots & \ldots & \ldots & \ldots & \ldots & \ldots & \ldots \\
\text { Cataluña } & \ldots & \ldots & \ldots & \ldots & \ldots & \ldots & \ldots & \ldots \\
\text { Baleares } & \ldots & \ldots & \ldots & \ldots & \ldots & \ldots & \ldots & \ldots \\
\text { Valencia } & \ldots & \ldots & \ldots & \ldots & \ldots & \ldots & \ldots & \ldots \\
\text { Madrid } & \ldots & \ldots & \ldots & \ldots & \ldots & \ldots & \ldots & \ldots\end{array}$ & $\begin{array}{l}64,8 \\
61,1 \\
61,1 \\
60,6 \\
54,2\end{array}$ & $\begin{array}{l}21,6 \\
35,8 \\
34,8 \\
36,3 \\
35,9\end{array}$ & $\begin{array}{l}77,3 \\
76,7 \\
51,4 \\
66,0 \\
81,9\end{array}$ & $\begin{array}{r}10,0 \\
7,6 \\
3,8 \\
4,8 \\
14,3\end{array}$ \\
\hline $\begin{array}{l}\text { Regiones con menor nivel de } \\
\text { consumo: }\end{array}$ & & & & - \\
\hline 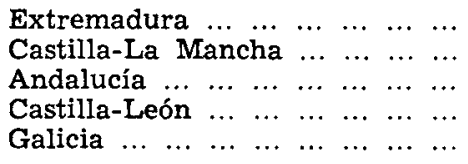 & $\begin{array}{l}35,1 \\
40,7 \\
42,7 \\
44,7 \\
46,2\end{array}$ & $\begin{array}{l}14,2 \\
15,8 \\
24,0 \\
16,1 \\
12,2\end{array}$ & $\begin{array}{l}34,0 \\
43,8 \\
56,4 \\
52,4 \\
47,7\end{array}$ & $\begin{array}{l}3,6 \\
2,8 \\
3,7 \\
4,1 \\
3,8\end{array}$ \\
\hline
\end{tabular}

FUENTE: INE, Encuesta de presupuestos familiares 1980-1981, op. cit., tomo II, pp. 216-217 (elaboración propia).

En resumen, pues, podemos decir que actualmente en España se ha difundido una mentalidad de sociedad de consumo, al tiempo que tienden a incrementarse de manera muy notable los niveles de posesión de bienes de consumo, sobre todo en las zonas y regiones más prósperas y, en general, en las áreas urbanas y metropolitanas.

Especialmente el período 1975-1981 puede considerarse, a la luz de los datos disponibles, como un período de consolidación de unos niveles altos de consumo, y también de mejora en las condiciones de las viviendas de la mayoría de los españoles. Ciertamente los datos correspondientes a las condiciones de las viviendas desde 1968 a 1981 , que se recogen en la tabla 13, permiten comprobar cómo en el período que se corresponde con los primeros años de la transición democrática, pese a las adversas condiciones económicas, se ha reducido muy considerablemente la proporción de viviendas sin agua, sin servicios de higiene, etc., careciendo de electricidad en 1981 solamente un 1 por 100 de las viviendas, en comparación con el 20,5 por 100 en 1950 y el 16 por 100 en 1960 .

${ }^{36}$ INE, Encuesta de presupuestos familiares, op. cit., tomo II, p. 218. 
En su conjunto, puede decirse que las viviendas españolas carentes del confort mínimo (ni agua corriente, ni retrete), han pasado de ser el 39,5 por 100 en 1950 y el 16,1 por 100 en 1970 , al 7 por 100 en $1981^{37}$.

\section{TABLA 13}

Evolución de las condiciones de las viviendas

\begin{tabular}{|c|c|c|c|}
\hline & 1968 & 1975 & $1980-1981$ \\
\hline & $\%$ & $\%$ & $\%$ \\
\hline 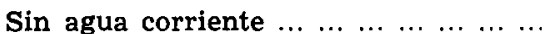 & 34 & 13 & 4 \\
\hline 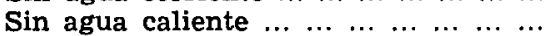 & 48 & 37 & 19 \\
\hline Sin servicios de higiene $\ldots \ldots \ldots \ldots \ldots \ldots$ & 35 & 17 & 7 \\
\hline $\begin{array}{llllllll}\text { Sólo con retrete } & \ldots & \ldots & \ldots & \ldots & \ldots & \ldots & \ldots\end{array}$ & 28 & 10 & 2 \\
\hline $\begin{array}{llllllllll}\text { Sólo con } \text { aseo } & \ldots & \ldots & \ldots & \ldots & \ldots & \ldots & \ldots & \ldots\end{array}$ & 16 & 15 & 7 \\
\hline $\begin{array}{lllllllll}\operatorname{Sin} \text { teléfono } & \ldots & \ldots & \ldots & \ldots & \ldots & \ldots & \ldots & \ldots\end{array}$ & 81 & 66 & 49 \\
\hline 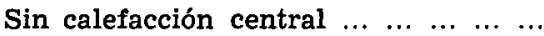 & 97 & 94 & 91 \\
\hline
\end{tabular}

FUente: INE, Encuesta sobre presupuestos familiares 1980-1981, op. cit., tomo II, pp. 52-54; Encuesta sobre equipamiento y nivel cultural de las familias 1975, op. cit., p. 42; ibídem, 1968 p. 157.

En definitiva, los datos correspondientes a evolución de los niveles de renta de los españoles, a estructura de presupuesto familiar, a posesión de determinados bienes y a condiciones de las viviendas, no permiten hablar, ni mucho menos, de un proceso objetivo de empobrecimiento de la población española en los últimos años, como a veces se ha venido postulando «interesadamente» desde determinados sectores. La verdad es que, en términos sociológicos reales, los españoles durante los primeros años de la transición democrática han visto elevado su nivel de vida objetivo de una manera significativa. Lo cual, sin duda, es algo que debe ser tenido en cuenta en el análisis sociológico y político, máxime cuando se produce en un contexto general de aguda crisis económica internacional.

No obstante, tal situación es preciso situarla, a su vez, en un marco social más amplio, en el que se puede constatar la persistencia, no sólo de importantes desigualdades regionales -incluso en lo referente a condiciones de las viviendas, tal como podemos ver en los datos de la tabla 14-, sino también de tremendas situaciones de pobreza y marginación social iy, lo que es más grave, de incultura y analfabetismo! Así, por ejemplo, según datos del censo de 1981, la cifra de analfabetos totales entre la población española de más de 10 años es de 2.044 .661 personas, a los que hay que sumar

${ }^{37}$ INE, España. Panorámica social 1974, op. cit., p. 368; Encuesta sobre presupuestos familiares 1980-1981, op. cit., tomo II, pp. 122 y 134. 
5.947.378 que no han cursado ni cursan ningún estudio, llegando la tasa de analfabetismo al 10,98 por 100 entre las mujeres, al 10,44 por 100 entre los que tienen entre 55 y 64 años, iy nada menos que al 21,50 por 100 entre los mayores de 65 años! Pero ciertamente el analfabetismo no puede ser considerado solamente como una lacra del pasado, como lo demuestra el hecho de que entre la población con edades comprendidas entre los 10 y los 34 años haya 193.502 analfabetos totales, así como 1.121 .109 personas que no cursan ni han cursado ningún estudio, a los que hay que sumar otros 189.559 analfabetos totales y 1.010 .913 personas sin estudios entre los que tienen entre 35 y 44 años. $Y$ también en este caso las mayores tasas de analfabetismo se producen en provincias como Jaén (15,7 por 100), Córdoba (13,8 por $100)$, Ciudad Real (13,3 por 100), Cáceres (11,9 por 100), Sevilla $(11,6$ por 100$)$, Badajoz $(11,6$ por 100$)$, etc. ${ }^{38}$.

\section{TABLA 14}

Condiciones de las viviendas en 1981 por-regiones

\begin{tabular}{|c|c|c|c|c|}
\hline & $\begin{array}{l}\text { Sin agua } \\
\text { corriente }\end{array}$ & $\begin{array}{l}\text { Sin servicios } \\
\text { de higiene }\end{array}$ & Sin teléfono & $\begin{array}{c}\text { Sin } \\
\text { electricidad }\end{array}$ \\
\hline Regiones prósperas: & $\%$ & $\%$ & $\%$ & $\%$ \\
\hline $\begin{array}{llllll}\text { Navarra } & \ldots & \ldots & \ldots & \ldots & \ldots \\
\text { Cataluña } & . . & \ldots & \ldots & \ldots & \ldots \\
\text { Baleares } & . . & \ldots & \ldots & \ldots & \ldots \\
\text { Valencia } & . . & \ldots & \ldots & \ldots & \ldots \\
\text { Madrid } & \ldots & \ldots & \ldots & \ldots & \ldots\end{array}$ & $\begin{array}{l}- \\
1 \\
2 \\
1 \\
1\end{array}$ & $\begin{array}{l}-1 \\
8 \\
2 \\
1\end{array}$ & $\begin{array}{l}\mathbf{4 1} \\
34 \\
52 \\
52 \\
18\end{array}$ & $\begin{array}{l}- \\
- \\
-\end{array}$ \\
\hline Regiones pobres: & & & & \\
\hline 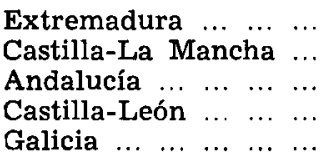 & $\begin{array}{r}11 \\
6 \\
6 \\
3 \\
9\end{array}$ & $\begin{array}{l}24 \\
18 \\
10 \\
16 \\
21\end{array}$ & $\begin{array}{l}72 \\
69 \\
69 \\
60 \\
70\end{array}$ & $\begin{array}{r}1 \\
2 \\
2 \\
1\end{array}$ \\
\hline
\end{tabular}

FUENTE: INE, Encuesta sobre presupuestos 1980-1981, op. cit., tomo II, pp. 52-54.

\section{Otros cambios sociales}

Finalmente, junto a todo lo anterior, durante estos últimos años se han producido también en España un conjunto muy amplio de otros cambios sociales importantes, aparte, claro está, de los que están más directamente vinculados a la dinámica política del sistema.

${ }^{36}$ INE, Censo de Población 1981, op. cit., pp. 35, 76 y 104. 
Entre los muchos cambios —que no son sino diversas facetas de un importante proceso de transformación social global-, es preciso mencionar los cambios de mentalidad en las nuevas generaciones, que han ido asumiendo los modelos culturales predominantes en los países occidentales. Estos cambios tienen una dimensión más epifenoménica (músicas, modas costumbres, gustos, etc.) y otra más ideológica y cultural (definición de nuevos valores y planteamientos sociales y comunitarios, etc.), que, conjuntamente, han contribuido a producir un importante desfase en las mentalidades de las diferentes generaciones, dando lugar a importantes incomunicaciones y nada despreciables conflictos generacionales. Igualmente se ha ido produciendo una progresiva crisis de los llamados «valores tradicionales», y en especial -como ha señalado Giner- la "reducción de la ideología imperialista tradicionalista» ${ }^{39}$. Ciertamente la evolución de la Iglesia a partir del Concilio Vaticano II, y, más en concreto, la experimentada en algunos ambientes católicos, así como la paralela tendencia a la secularización de la sociedad española, es una de las transformaciones más importantes ocurridas en nuestro país en los últimos tiempos, y que más ha contribuido al cambio de mentalidades, una vez quebrada la vigencia social de las viejas ideologías religioso-puritanotradicionales, que tanto han venido influyendo históricamente en amplios sectores de población.

Un buen ejemplo del nivel de secularización y de desconflictualización de las relaciones religioso-políticas en la España actual, lo constituye el mismo grado de diversidad religiosa que se produce entre los electores y los propios afiliados de los partidos de izquierda ${ }^{40}$. De hecho, los análisis sociológicos más recientes permiten constatar que la influencia de los factores religiosos en el comportamiento político de los españoles es extraordinariamente más débil de lo que fue hasta hace muy pocos años, si bien no faltan quienes estiman que cualquier movilización electoral en torno a estos temas podría hacer «reaparecer» un fuerte componente de conflicto y división ${ }^{41}$.

Otro cambio importante, en parte asociado a los cambios de mentalidad, ha sido la modificación - aunque lenta e insuficiente- en la situación social de la mujer, que ha logrado, al menos, romper muchas inercias y prejuicios tradicionales e irse incorporando progresivamente al mundo del trabajo, aun a pesar de que la tasa de empleo femenino en España sea mucho más baja

${ }^{39}$ Salvador Giner, La estructura social de España. Horizonte español 1972, París, 1972, tomo 2, p. 43.

40 Véanse José Félix Tezanos, Sociología del socialismo español, Madrid, Tecnos, 1983, pp. 86-87 y 115-117, y Abel Hernández, Crónica de la Cruz y de la Rosa (Los socialistas y la Iglesia, hoy), Madrid, Argos Vergara, 1984, pp. 53-66.

"Juan J. Linz, Manuel Gómez Reino, Francisco A. Orizo y Darío Vila, Informe sociológico sobre el cambio político en España, 1975-1981, Fundación FOESSA, Madrid, Euramérica, 1981. Véanse especialmente pp. 289-308. Estos autores, desde el horizonte de 1981 , valoraban de manera más intensa la relación entre la religión y política, antes de producirse la descomposición de UCD y el fuerte ascenso electoral del PSOE en 1982. 
que en otros países europeos e industrializados y que las condiciones de crisis económica a partir de 1975 no hayan favorecido este proceso ${ }^{42}$.

Igualmente se han producido también importantes transformaciones en la concepción y el perfil social tradicional de la familia: la familia no sólo tiende a hacerse cada vez más reducida, nuclear y aislada, sino que también se difunden nuevas formas de relaciones de pareja, se liberalizan las relaciones sexuales y aumenta el grado de independencia de los hijos, manifestándose nuevas formas de convivencia en grupo, en pareja o individualmente entre su número creciente de jóvenes ${ }^{43}$.

Especial mención hay que hacer también a las nuevas formas de manifestación de toda la problemática regional y autonómica, que tras los años en tantos aspectos tan asfixiantemente centralizadores del franquismo, han dado lugar al surgimiento -o intensificación- de importantes sentimientos autonómicos en prácticamente todas las regiones españolas; unas veces con más énfasis en tradiciones políticas y culturales enraizadas, y otras más vinculadas a toda la problemática sociopolítica derivada de la profundamente desigualitaria distribución regional de la riqueza ${ }^{44}$.

$\mathrm{Y}$ para terminar, con este inventario - necesariamente incompleto- de cambios sociales es preciso mencionar, al menos, todos aquellos asociados a los cambios económicos y a los procesos sociales anteriormente reseñados: la nueva conformación de la población activa, la mayor participación de la mujer en ésta, el cambio en la mentalidad y el tipo de empresario (en cuyos extremos podemos decir que hemos pasado del empresariado del «estra-

42 Sobre este tema, véanse María Angeles DuRÁn, El trabajo de la mujer en España, Madrid, Tecnos, 1972, y más recientemente el estudio de Pilar Alcobendas Tirado, Datos sobre el trabajo de la mujer en España, Madrid, Centro de Investigaciones Sociológicas, 1983.

${ }^{43}$ Una encuesta realizada por Salustiano del Campo y Manuel Navarro en 1980 daba, en su conjunto, unas estimaciones de 1.299 .867 personas que vivían solas, 68.286 que vivían en grupo mixto, 90.235 cohabitando y 356.061 en otras formas diferentes a la familia. Lógicamente, es de suponer que la fuerte reducción de la tasa de nupcialidad experimentada en España a partir de 1980, tal como vimos anteriormente, estará teniendo también su traducción en el aumento de estas prácticas de vida. Véase Salustiano del Campo y Manuel Navarro, Análisis sociológico de la familia española, Madrid, Ministerio de Cultura, 1982, p. 18. Sobre el tema de la familia pueden verse también, recientemente, los libros de Inés Alberdi, Historia y sociologia del divorcio en España, Madrid, Centro de Investigaciones Sociológicas. 1978; Salustiano del CAMPo, El ciclo vital de la familia española, Madrid, Real Academia de Ciencias Morales y Políticas, 1980, y Rosa CoNDE (ed.), Familia y cambio social en España, Madrid, Centro de Investigaciones Sociológicas, 1982.

${ }_{44} \mathrm{La}$ literatura sobre la problemática regional es, en nuestro país, bastante abundante. El resultado de dos amplias investigaciones sociológicas sobre el tema en los cruciales años del inicio de la transición pueden verse en Salustiano del Campo, Manuel Navarro y José Félix Tezanos, La cuestión regional española, Madrid, Edicusa, 1977; José Jiménez Blanco, M. García Ferrando, E. Lópecz Aranguren y Miguel Beltrán, La conciencia regional en España, Madrid, CIS, 1977. Más recientemente, véanse, por ejemplo, Manuel García Ferrando, Regionalismo y autonomía en España, 1976-1979, Madrid, CIS, 1982, y Francesc Hernández, La identidad nacional en Cataluña, Barcelona, Vicens Vives, 1983. 
perlo», al mundo de los jóvenes ejecutivos y tecnócratas del neocapitalismo) ${ }^{45}$, el aumento de nuevos tipos de conductas delincuentes (especialmente las delincuencias juveniles: violencia de pandillas, robos de coches, agresiones sexuales, etc.), la nueva problęmática educacional surgida como consecuencia de la crisis de crecimiento y ajuste a las nuevas necesidades, las nuevas formas de inversión del ocio, las mayores posibilidades de mejora social y movilidad social, la incidencia creciente de los medios audiovisuales de comunicación, la mayor intercomunicación y apertura de los ciudadanos hacia todos los problemas e ideas dimanantes del contexto europeo e internacional, etc.

\section{Las consecuencias del cambio social y el reto de la modernización}

A nadie se le oculta que las consecuencias de unos procesos de cambio sociales tan fenomenales como los que España ha experimentado en unos pocos años son muchas e importantes.

Sociólogos y politólogos han venido coincidiendo en señalar como uno de los aspectos más llamativos de la situación española de los últimos años del franquismo fue la diacronía implícita entre el crecimiento económico y el cambio social y la persistencia de una correlativa falta de cambio político y modernización. Ciertamente en los últimos años del franquismo España cambió mucho en los aspectos sociales y económicos, pero apenas cambió en los aspectos políticos. España, en cuanto realidad social, se había convertido en algo muy distinto a lo que era unos años antes, mientras que las bases del sistema político franquista persistieron prácticamente inalteradas, superponiéndose tanto a los problemas del crecimiento económico, como a los derivados de las tensiones de desarrollo, de los múltiples problemas sociales, de la inflación, del paro, de la más justa distribución de la riqueza, etc. Es decir, de todo lo que boy en día son los acuciantes problemas que preocupan a la mayoría de los ciudadanos españoles, seriamente preocupados por la necesidad de empezar a remontar la grave crisis económica en que quedó sumido el país en las postrimerías del franquismo. Obviamente, los problemas económicos y sociales en este momento histórico no han surgido de repente, sino que son el resultado de muchos errores acumulados y, en su conjunto, de la peculiar manera en que los gobernantes franquistas abordaron toda la problemática del crecimiento económico y del cambio social.

No cabe duda que la puesta en marcha de un proceso de crecimiento económico y cambio social como el que España experimentó durante la década de los 60 y la primera mitad de los 70 era una magnífica oportunidad para plantearse seriamente la actuación sobre un conjunto muy diverso de factores sociales que hubieran permitido superar muchos de los desajustes,

${ }^{45}$ Sobre este tema, véase, por ejemplo, F. de la Sigrra, J. Carallero y J. P. EsCAMILla, Los directores de las grandes empresas españolas ante el cambio social. Madrid, CIS, 1981. 
desequilibrios y problemas estructurales del sistema económico y social. Sin embargo, casi todo fue dejado en manos de la espontaneidad y el azar, de forma que el tránsito desde una sociedad agraria tradicional a una sociedad industrial se produjo de una manera bastante caótica y desordenada, dando lugar a numerosas tensiones, conflictos y desajustes: problemas de los desplazamientos de población, agudización de desigualdades, crisis de la agricultura, problemas del crecimiento «salvaje» de algunas ciudades que han dado lugar a poblamientos sin adecuados servicios urbanos, sin escuelas, etc. Todos los problemas sociales apuntados en este capítulo, y otros muchos que ni siquiera hemos mencionado, han de ser vistos, pues, como algunos de los frutos de una política cuyas consecuencias sociales costará años enderezar.

Pero, sin embargo, junto a estos aspectos más negativos y problemáticos del proceso de cambio social español, es preciso tener en cuenta que España se ha transformado profundamente y muchas de las pesadas cadenas que la mantenían atada a un pasado cuasimedieval han sido rotas, habiéndose puesto las suficientes bases económicosociales nuevas como para que los españoles puedan afrontar la construcción de un futuro distinto, sin temor a caer una vez más en períodos de obscurantismo y regresión histórica. ¿Podemos decir, pues, que la estructura social se ha modernizado? Ciertamente aún no se puede dar una contestación positiva a esta pregunta, como lo demuestra el mismo hecho de que el objetivo de la modernización continúe siendo una de las metas políticas fundamentales de la España actual. Si bien es cierto que es preciso reconocer que la estructura social española se ha transformado bastante radicalmente, y que dicha transformación tiene importantes consecuencias sociales y políticas.

A mediados de la década de los 70 , no solamente no se podía hablar con rigor de una clara modernización, sino que la dinámica de los hechos demostró la necesidad de afrontar un conjunto muy amplio de reformas que hicieran posible la misma funcionalidad del sistema económico y social. Una buena parte de estas reformas, especialmente las de signo político, han venido siendo acometidas desde 1977, pero sin duda aún son muchas las que es preciso desarrollar para hacer de la sociedad española una sociedad verdaderamente moderna y capacitada para enfrentarse eficazmente a los múltiples retos del mundo actual, cuando ya se barrunta en el horizonte el despuntar del siglo xxi. Se ha dicho, con razón, que la década de los 60 podrá pasar a la historia de España como la década del crecimiento económico, y la de los 70 como la década del cambio político; ahora es preciso comprender que la década de los 80 debe ser la década de la modernización social. Lo cual implica, no sólo la puesta a punto del sistema económico y social, sino también la consolidación del régimen político democrático, la modernización del Estado, la reforma educativa y, claro está, y no como lo menos importante, la superación de las hirientes desigualdades regionales y personales persistentes aún, así como las de aquellas situaciones de pobreza, mar- 
ginación social e incultura en las que todavía se encuentran sumidos millones de españoles.

La modernización, en este sentido, no puede ser entendida en la España actual, de manera restringida y formal, como ha ocurrido en algunos círculos sociológicos y políticos ${ }^{46}$, sino que debe ser situada en un horizonte histórico mucho más dilatado, en el que se entremezclan objetivos funcionales inmediatos -en torno a los cuales puede existir, lógicamente, una amplia franja de acuerdo- con otros directamente enlazados con los grandes objetivos de transformación social de una nueva izquierda decantada de ingenuidades y misticismos milagreros y que entiende la modernización como una etapa necesaria en la perspectiva de una más amplia tarea progresiva de cambio profundo a largo plazo.

Asimismo, es preciso tener en cuenta que la asunción del objetivo de modernización por la izquierda no está limitado a los partidos socialistas, sino que forma parte también de la actual sensibilidad política, y de la misma práctica, de buena parte de los partidos comunistas europeos, como ha sabido subrayar ya la literatura científica sobre el tema ${ }^{47}$.

Aunque aquí no es posible entrar en las cuestiones de fondo sobre la problemática teórica de la modernización, podemos afirmar, aun a riesgo de simplificar en exceso, que la diferencia entre un enfoque conservador de la modernización y uno progresista, es que en el primer caso el diseño de la modernización se traza un tanto mecanicistamente desde la economía y la preocupación fundamental es cómo «absorber» los conflictos y cómo «encauzar» las corrientes de cambio, mientras que en el segundo caso, no sólo no se hace una lectura negativa del conflicto y del cambio, sino que se pretende potenciar y racionalizar las posibilidades de cambio insitas en el sistema, orientadas hacia objetivos no exclusivamente economicistas.

${ }^{46}$ Los objetivos de la modernización, obviamente, no deben ser limitados a lo que han sido los planteamientos propios de determinados círculos de la "sociología de la moderniación" (Apter, Germani, Moore, Eisenstadt, etc.), ni tampoco, claro está, a lo que han sido algunas de las derivaciones políticas con que a veces se ha intentado aplicar, no sin cierta ingenuidad, como ocurrió en España, por ejemplo, con algunos de los tecnócratas del Opus Dei, durante la etapa del "desarrollismo".

${ }_{47}$ Véase, por ejemplo, Franco Ferrarotri, "The modernizing role of the working-class parties in Southern Europe", en Bogdan DeNITCH (ed.), Democratic socialism, The mass left in advanced industrial societies, New Jersey, Allanheld, Osmun \& Co. Totowa, 1981, pp. 104-116. 